\section{Abstract} energy.

\title{
Quasi-static bending and low velocity impact performance of monolithic and laminated glass windows employing chemically strengthened glass
}

\author{
I. Mohagheghian ${ }^{1}$, Y. Wang ${ }^{1}$, L. Jiang ${ }^{2}$, X. Zhang ${ }^{2}$, X. Guo ${ }^{2}$, Y. Yan ${ }^{2}$, A.J. Kinloch ${ }^{1}$ and J. P. \\ Dear $^{1}$ \\ ${ }^{1}$ Department of Mechanical Engineering, Imperial College London, London SW7 2AZ, United Kingdom \\ ${ }^{2}$ Beijing Institute of Aeronautical Materials, AVIC, Beijing 100095, China
}

In this paper, firstly the quasi-static bending performance of chemically strengthened alumina silicate glass plates is investigated for different glass thicknesses: 2.2, 4.0 and $6.0 \mathrm{~mm}$. The flexural strength is measured using coaxial double ring experiments. The 3D Digital Image Correlation (DIC) technique is employed to measure the strain at failure. The failure probability is then assessed using the Weibull statistical distribution.

Secondly, the performance of the laminated glass windows made of these chemically strengthened glass plates is evaluated quasi-statically under concentrated and distributed loadings. The effects of polymer interlayer thickness, glass and polymer type and multilayering the polymer interlayer on the structural performance are investigated. The type and thickness of the polymer interlayer, as well as the type of loading are found to influence the fracture sequence in the glass plates and consequently the post fracture safety of the structure. The response of laminated glass specimens is then assessed under low velocity soft impacts, for velocities up to $3.3 \mathrm{~m} \mathrm{~s}^{-1}$, using a drop tower facility. Laminated glass with a polyvinyl butyral (PVB) interlayer shows the greatest improvement in terms of peak force and absorbed 
Keywords: Coaxial double ring, Chemically strengthened glass, 3D DIC, Laminated glass, Soft impact

\section{1- Introduction}

The development of chemically strengthened glass has created great opportunities for designing thin, strong and lightweight transparent structures. Nowadays, chemically strengthened glasses have found their way into the market in many different applications including aircraft cockpit windshields, photocopier scanner glass, display windows in cell phones (Varshneya, 2010), high-speed train windshields, glass substrates for hard-disk drive fabrication and glass items for drug delivery (Gy, 2008), with more potential applications still yet to come.

Chemically strengthening is based on the concept of ion exchange for which small cations, initially present in the glass, are replaced by larger cations from a molten salt (Hale, 1968). This creates a compressive layer with the depth of few micrometres. An effective ion-exchange process was first introduced by Kistler (1962) by replacing $\mathrm{Na}^{+}$in the surface of the glass with larger $\mathrm{K}^{+}$ions. They achieved compressive stresses up to $855 \mathrm{MPa}$ for soda-lime glass. Chemically strengthening is found to be most effective for lithium and/or sodium aluminosilicate glasses, producing surface compressive stresses up to $1 \mathrm{GPa}$ (Varshneya, 2010). This technique has several advantages over other strengthening methods such as thermal strengthening. It can create relatively high compressive surface stresses without any optical distortion (Varshneya, 2010) and can be applied to very thin glasses and complex geometries (Varshneya, 2010). The main disadvantage of the technique is the high cost of the process which limits its application to high-end products (Gy, 2008). 
The high strength of chemically strengthened glasses makes it possible to have thinner glass plates and consequently lighter transparent structures. However, this creates a new challenge for characterising these thin and strong materials (Connolly et al., 1989; Gulati et al., 2002; Kao et al., 1971; Vepakomma et al., 2013; Wilcox et al., 2013). Large deflections and consequently the development of membrane stresses in thin plates means that conventional analysis methods (ASTM C 1499-03, 2015; British Standard, 2000), which are based on linear bending theory, lose their validity. Different approaches including more advanced analytical (Inoue et al., 1991; Kao et al., 1971), finite element (Connolly et al., 1989; Vepakomma et al., 2013) and experimental methods (Vepakomma et al., 2013) have been employed to solve this problem. By considering the effect of membrane stresses in their analysis, Kao et al. (1971) derived a non-linear analytical model. An analytical approach was also used by Inoue et al. (1991). Good agreement was observed between the model predictions and experimental results in both studies. Connolly et al ( 1989) used the finite element method and extracted the strength of chemically strengthened and non-strengthened glass disks by comparing numerical and experimental results. Vepakomma et al. (2013) investigated the flexural bending strength of a LCD panel using ring-on-ring experiments. Finite element analysis in combination with strain measurements, using strain gauges, was employed to capture the non-linear behaviour of thin glass plates.

A more direct experimental approach of measuring the failure strain has not been reported in the existing literature due to difficulties with strain gauge measurements. Since, for measuring failure strains using strain gauges, the location and the direction of the maximum strain need be known in advance and the gauge should be placed exactly at that location. This is especially more difficult for thin glasses as failure may occur somewhere away from the centre of the specimen. Also, due to the probabilistic nature of glass failure, a large number of experiments 
are needed for strength characterisation of these glass plates. This makes using strain gauges even more difficult with respect to the time and costs involved.

Wherever safety is a concern, glass plates are used in the form of a laminate. Laminated glass normally consists of two layers of glass plates and one layer of polymer, which is sandwiched between the two glass plates. The polymer interlayer maintains the structural integrity of the component after breakage of the glass plates and protects the surroundings from the flying fragments. Apart from the safety aspect, laminated glass has also other structural as well as non-structural advantages compared to monolithic glass including better impact resistance, sound attenuation and ultraviolet radiation absorption (Behr et al., 1993). Laminated glass is used in many engineering applications including automobile and aircraft windshields, architectural and security glazing. Various polymers are used in industry including polyvinyl butyral (PVB), thermoplastic polyurethane (TPU), ethylene-vinyl acetate (EVA) and ionoplast SentryGlas ${ }^{\circledR}$ Plus (SGP). Amongst all interlayers, SGP has been found to have a superior structural performance at room temperature (Bennison et al., 2008, 2001). As a result, the use of this polymer interlayer is increasing particularly for architectural applications.

The structural performance of a laminated glass is significantly influenced by loading duration and testing temperature, because of their effect on the viscoelasticity of the polymer interlayer (Behr et al., 1986; Hooper, 1973; Walley et al., 2004). Depending on the shear stiffness of the polymer interlayer, the laminated glass performance can vary between two limits. The lower and upper limits correspond to the performance of two independent glass plates and monolithic glass of equivalent thickness (total thickness of glass and polymer layers) respectively.

The sequence of failure, post-glass breakage behaviour and structural integrity of laminated glass windows are other important aspects of their structural performance, particularly in terms of safety. Bennison et al. (1999) investigated in detail the sequence of failure in glass plates for 
a laminated glass with a PVB interlayer. Bennison et al. (1999) found that the location of the maximum stress, and consequently the sequence of failure in the glass plates, can change depending on the test temperature and loading rate. Belis et al. (2009) studied the failure mechanisms and post-glass breakage of laminated glass with a SGP interlayer. The post-failure safety was found to be poor, despite the superior mechanical properties of the SGP (Belis et al., 2009). Overend et al. (2014) studied the post-fracture behaviour of laminated hybrid-glass units consisting of three layers of glass and two layers of polymer. PVB and SGP were used for the polymer interlayer. Contrary to the results of Belis et al. (2009), Overend et al. (2014) observed the largest post-fracture stiffness for laminated glass with a SGP interlayer.

Laminated glass can be exposed to low velocity impacts by hard as well as soft projectiles. The term "hard impact" refers to an impact in which the deformation of the projectile is negligible compare to that of the target. In contrast, when the projectile undergoes extensive deformation during its interaction with the target, the impact is called "soft impact". The impact can also be categorised according to its velocity range into "low" and "high" velocity. According to Backman and Goldsmith (1978), the term "low velocity" refers to impacts with velocities less than $25 \mathrm{~m} \mathrm{~s}^{-1}$. The impact by large windborne objects on architectural glass windows or pedestrian head impact to car windshield can be classified in this category. The term "high velocity" is referred to impacts with velocities greater than $25 \mathrm{~m} \mathrm{~s}^{-1}$ and can be further subdivided into three velocity ranges: sub-ordnance velocities $\left(25-500 \mathrm{~m} \mathrm{~s}^{-1}\right)$, ordnance velocities (500-1300 $\mathrm{m} \mathrm{s}^{-1}$ ) and ultra-ordnance velocities (1300-3000 $\mathrm{m} \mathrm{s}^{-1}$ ) (Backman and Goldsmith, 1978).

Despite detailed studies on the performance of laminated glass against hard impactors (Behr et al., 1999; Flocker and Dharani, 1998; Grant et al., 1998; Ji and Dharani, 1998; Kaiser et al., 2000; Saxe et al., 2002), far less attention has been paid towards soft impact response of these structures. Dharani and Yu (2004) and Zhang et al. (2013) investigated the impact response of 
laminated glass against impact by large soft projectiles such as collapsed trees or ceiling wood flying during hurricanes. Dharani and Yu (2004) suggested that that for a large and soft projectile, bending stresses at the opposite surface to the impact are responsible for the failure. This is in contrast to a hard impact where the failure is initiated by Hertzian contact stresses. The failure mode is also influenced by the nose shape of the impactor. Two nose shapes: hemispherical and blunt were considered (Dharani and $\mathrm{Yu}, 2004)$. Whilst for a soft hemi-spherical impactor, failure occurs at the back side of the outer glass plate, for a soft blunt impactor, the failure is initiated at the back side of the inner layer. Zhang et al. (2013) argued that the thickness of the polymer interlayer plays a dominating role in the penetration resistance of laminated glass windows against windborne wooden block impact. Shetty et al. (2012) numerically investigated the impact response of laminated glass windows for both soft and hard impacts. They concluded that in both cases, the thinner outer glass plate results in a better pre-failure stress pattern than a thicker glass plate. A thicker polymer interlayer also generally lowers the stresses in the critical areas. Pacios et al. (2011) investigated the soft impact response of monolithic as well as laminated glasses using a $50 \mathrm{~kg}$ twin-tyre pendulum at a speed up to $4.85 \mathrm{~ms}^{-1}$. The effect of glass type and thickness, boundary conditions, and dimensions of the glass plates were studied. The height of impact had been gradually increased until the specimen broke. It was found that the loading, e.g. the shape of strain and acceleration traces, is significantly influenced by the boundary condition (e.g. four pin supported compared to two sides supported). Increasing the height of the drop of the impactor, however, only increases the level of strain and force without any change in the shape of the trace for a specific boundary condition.

Pedestrian head impact on a car windshield can also be categorised as a low velocity soft impact. Normally, laminated glass are tested against a headform consisting of a hollow 
et al. (2006) numerically studied the response of laminated glass against pedestrian head 147 impact. They argued that the thickness of the inner glass layer (non-impacted side) is an important design parameter determining the impact resistance of the structure. On the other hand, the thickness of the outer glass layer (impacted side) and PVB interlayer has no significant effect on the impact resistance.

151 In this paper, the focus will be on the quasi-static bending as well as low velocity impact 152 performance of monolithic and laminated glass plates made of chemically strengthened glass. These less well studied aeronautical materials are normally used for manufacturing aircraft windshields and have superior structural and impact resistance properties. In this study, we use 3D digital image correlation technique to experimentally measure the failure strain of the specimen as well as monitoring the full-field displacement and strain development throughout the deformation. Through a systematic study, the influence of various design parameters including the glass and polymer type, the polymer interlayer thickness and multi-layering the interlayer is investigated on the stiffness, strength and sequence of failure of the laminated glass structure. The effect of type of loading on quasi-static bending is also investigated by applying concentrated as well as distributed loading. The performance of various constructions of laminated glass are then assessed under low velocity soft impact. Finite element simulation is used to gain further understanding on the impact performance of laminated glass with three different polymer interlayers. The numerical results are shown to be in very good agreement with the experimental results.

\section{2- Materials}


The chemically strengthened glass plates used in this study were manufactured using alumina silicate float glass. The glass, which was initially edge smoothed, was soaked in potassium salt solution for ion exchange at $420^{\circ} \mathrm{C}$ for 5 hours at the Beijing Institute of Aeronautical Materials (BIAM). This resulted in the formation of compressive layers with a depth of $38 \mu \mathrm{m}$ and strength of $738 \mathrm{MPa}$ on the glass surfaces. The residual stresses were measured in BIAM by the optical birefringence technique, using Orihara surface stress meter model FSM-6000LE. Only the strength and depth of compressive layer were measured (i.e. the distribution of through-thickness residual stress was not measured). In this paper, all glass plates have the same ion-exchange time and consequently the same compressive layer on their surfaces. The effect of various values of residual stress on the fracture of chemically strengthened glass plates was investigated in a separate paper (Jiang et al., 2017).

The monolithic glass plates were manufactured with the dimensions of $100 \times 100 \mathrm{~mm}$ in three thicknesses: 2.2, 4.0 and $6.0 \mathrm{~mm}$. The glass plate size is selected based on the recommendation by the British standard (British Standard, 2000). Similar glass plates (but only for the 2.2 and $4.0 \mathrm{~mm}$ thick glass plates) were used for manufacturing the laminated glass specimens. The tin side of the glass plate was cleaned and used for lamination. Three types of polymer interlayers were employed: Thermoplastic Polyurethane (TPU) -KRYSTALFEX ${ }^{\circledR}$ PE499 (from Huntsman), Polyvinyl Butyral (PVB)-Butacite ${ }^{\circledR}$ (from DuPont) and Ionoplast interlayerSentryGlas ${ }^{\circledR}$ Plus (SGP) (from DuPont). The lamination was conducted using an autoclave at BIAM. Lamination was performed within the shelf-life time of the polymer interlayers which were stored in dry and cool conditions. In total, seven different laminated glass configurations were manufactured. The details of each configuration are listed in Table 1. Due to a limitation on the conventional polymer interlayer thickness available in the market, in some cases two layers of polymer were used to achieve the required interlayer thickness (Table 1). 


\section{3- Glass characterisation}

194 In order to measure the strength of chemically strengthened glass, a coaxial double ring test 195 (ring-on-ring) was employed. This flexural test has been found to give the most accurate measure of the strength amongst various biaxial testing methods (Ritter et al., 1980). The method is also preferred as it does not put large tensile stresses on the machined edges of the test specimens (Gy, 2008).

\section{3-1 Methodology}

For monolithic glass plate specimens, the tests were performed according to BS EN12885:2000 (British Standard, 2000). The square specimens with dimension of $100 \times 100 \mathrm{~mm}$ were tested at a constant loading rate of $10 \mathrm{~N} \mathrm{~s}^{-1}$. For monitoring the displacement and strain development in the bottom side of the specimen, 3D Digital Image Correlation (DIC) was employed. For this purpose, the conventional rig proposed by the British standard (British Standard, 2000) was modified. The schematic and photograph of the designed rig is shown in

Figure 1. To observe the bottom surface of the specimen, a flat and front-silvered mirror (from Edmund Optic Ltd) was employed. The mirror was located below the specimen (Figure 1) with a $45^{\circ}$ orientation with respect to the surface of the specimen. A transparent protective shield confined the specimen and rig to prevent glass fragments from flying off after fracture.

A 3D DIC set-up is shown in Figures $1 \mathrm{~b}$ and 1c. A pair of images were recorded with time intervals of $2 \mathrm{~s}$ by two cameras (ARAMIS 5M). The cameras were separated by $540 \mathrm{~mm}$ and were located with a working distance of $695 \mathrm{~mm}$ from the specimen (Figure 1c). It is to be noted that the working distance here is the summation of the distance between the cameras and mirror and that from the mirror to the surface of the specimen (Figure 1c). This results in an 
angle of $25^{\circ}$ between the two cameras which is the best recommended angle for stereo-vison measurement (Schreier et al., 2009). The cameras had lenses with a fixed focal length of 50 $\mathrm{mm}$ and captured images with the resolution of $2448 \times 2050$ pixels. To illuminate the back surface of the specimen, two LED light sources were used. These sources were located inside the transparent shield and illuminated the specimen from both sides. This was to prevent reflections from the protective shield.

To calculate the deformation using DIC, first a random speckle pattern was applied onto the surface of the specimen. The speckles were generated by spraying black paint onto a white painted surface, to generate the maximum contrast. An acrylic paint was used as it has enough ductility to stay adhered onto surface up to the point of glass fracture without any damage. The images were then processed using Aramis software and full-field deformation and strain contours were generated.

To validate the DIC results, a series of experiments was conducted using both the strain gauge and DIC methods. A FLA-2-8 strain gauge (from Techni Measure Ltd) was employed for this purpose. The strain gauge was adhered onto the surface of the glass prior to painting. The top surface of the gauge was painted and speckled and, therefore, its deformation could be monitored using DIC. Data acquisition was conducted using CompactDAQ (a portable data acquisition platform from National Instruments Ltd).

The loading fixture employed is shown in Figure 2. For concentrated loading (ring-on-ring), the dimensions of the rings are shown in Figure 2a. The supporting and loading rings have a diameter of 18 and $90 \mathrm{~mm}$ respectively. Both rings have a radius of curvature of $2.5 \mathrm{~mm}$ and were manufactured from stainless steel. To prevent stress concentrations developing and consequently premature failure of the specimen (British Standard, 2000), rubber gaskets with a thickness of $3 \mathrm{~mm}$ and a Shore Hardness A of 60 were placed between the specimen and the 
supporting ring. A thin layer of silicon tape was adhered on the top surface (i.e. the compressive side) of the specimen for retaining the fragments. As recommended by the British Standard (British Standard, 2000), a thin layer of paper was also placed between the loading ring and top surface of the glass. The displacement was recorded from the Instron cross head displacement and the force from the load cell connected to the upper ring, at a rate synchronised with the camera recording.

It should be noted that large deflections for the thinner glass can be reduced if a glass with smaller dimensions is used. This, however, requires using loading and supporting rings with smaller diameter which itself causes reduction in the size of the testing area at the centre of the plate. If the testing area becomes too small, the distribution of the surface flaws in the testing area might not be representative of that in the in-service glass panels. The bending strength is found to increase with decreasing the size of the testing area (Kondo et al., 2014). A method of considering the "size effect" in the strength measurements for ring-on-ring experiment is discussed by Jain et al. (2009).

\section{3-2 Results}

256 The strain development at the centre of the plate is compared for the three glass thicknesses in

257 Figure 3. The plot includes both DIC and strain gauge measurements. Good agreement exists between the two methods which confirms the validity of the DIC measurements. Since the experiments were performed at a constant loading rate $\left(10 \mathrm{~N} \mathrm{~s}^{-1}\right)$, the time taken for a $2.2 \mathrm{~mm}$ glass to fracture is shorter than for the 4.0 and $6.0 \mathrm{~mm}$ glass plates (as a result of the lower failure load). However, the level of failure strain is similar for all three thicknesses (Figure 3).

262 The out-of-plane displacement and major principal strain are plotted in Figure 4. The time to 

affects the strain development in $2.2 \mathrm{~mm}$ thick glass plates in the later stages of deformation, when the strain starts localising in the glass under the loading ring (Figure 4b). For the thicker glass plates, for which the maximum out-of-plane displacement is smaller (Figure 4a), the strain distribution is uniform at the centre of the plate. This can be more clearly seen in Figure 5 where the out-of-plane displacement and major strain profiles are plotted for a $2.2 \mathrm{~mm}$ thick glass plate. Each profile in Figure 5b corresponds to a load highlighted in Figure 5a. The strain localisation under the loading ring is apparent for loads greater than $2.3 \mathrm{kN}$. By this time, the centre of the plate is displaced by about $2.5 \mathrm{~mm}^{*}$ (Figure $5 \mathrm{~b}$ ) from its original position which exceeds the limitation of the linear bending theory. Deflections larger than one-quarter of the plate thickness according to (ASTM C 1499-03, 2015) and half of the plate thickness according to (Kao et al., 1971) can cause the development of membrane stresses in the specimen for which large deformation theory then needs to be considered.

The force against cross head displacement is plotted for the three glass thicknesses in Figure 6. For these experiments, the rubber spacer was removed. The compliance of the setup was measured by performing a compression test on a thick metal plate. This compliance was then subtracted from the measured cross head displacement during the coaxial double ring experiments. All the other test configurations are the same as that described in Section 3-1. The experimental results are compared in Figure 6 with the force versus displacement relationships

\footnotetext{
* Note that the cross head displacement in Figure 5a represents the displacement of the loading ring, measured from the point in the glass $9 \mathrm{~mm}$ away from the centre (Figure 2a). Therefore, its displacement values are different from that of the centre of the plate, especially for larger plate deflections.
} 
calculated using linear bending theory according to the following equation (ASTM C 1499-03, 2015; Vitman et al., 1963):

$$
F=\frac{8 \pi E h^{3} \delta}{3 D_{L}^{2}\left(1-v^{2}\right)}\left\{\frac{D_{S}^{2}}{D_{L}{ }^{2}}\left[1+\frac{(1-v)\left(D_{S}^{2}-D_{L}^{2}\right)}{2(1+v) D^{2}}\right]-\left(1+\ln \left(\frac{D_{S}}{D_{L}}\right)\right)\right\}^{-1}
$$

In the above equation $F, \delta, D_{S}$ and $D_{L}$ are the force, displacement, supporting and loading ring diameters respectively. The terms $E, v$ and $h$ are the Young's modulus, Poisson's ratio and the thickness of the plate, respectively. For a square test specimen $D$ is calculated by:

$$
D=\left(0.90961+0.12652 \frac{h}{D_{S}}+0.00168 \ln \left(\frac{l-D_{S}}{h}\right)\right)^{-1}
$$

where $l$ is the length of the test specimen (i.e. $100 \mathrm{~mm}$ ). In Equation 1, $E=72 \mathrm{GPa}$ and $v=$ 0.25 are considered (Li et al., 2014) to be appropriate values for chemically strengthened glass plates. As can be seen in Figure 6a, the experimental results start to deviate from a linear trend at a cross head displacement of approximately $1 \mathrm{~mm}$. The linear bending theory under predicts the force for displacements greater than $1 \mathrm{~mm}$. This deviation also occurs for $4.0 \mathrm{~mm}$ thick glass but at a larger displacement (ca. $1.5 \mathrm{~mm}$ ). For a $6.0 \mathrm{~mm}$ thick glass plate, the experimental results completely agree with those predicted by using Equation 1. Now, as a result of the large deformation, linear bending theory (ASTM C 1499-03, 2015) cannot be employed for calculating the failure strength of thin and strong glasses, e.g. the $2.2 \mathrm{~mm}$, and to some extent the $4.0 \mathrm{~mm}$, thick chemically strengthened glass used in the present work. Hence, in this paper, an experimentally-based approach is employed instead, and the strain is measured directly from the back surface of the specimen using DIC.

Due to the existence of defects and flaws on glass surfaces, glass strength measurements involve a relatively large degree of scatter. In order to determine the probability of failure, a 

expressed as:

$$
P_{f}=1-\exp \left[-\left(\frac{\varepsilon}{\varepsilon_{0}}\right)^{m}\right]
$$

305 306

307 308

where $P_{f}$ is the cumulative probability of failure at strain $\varepsilon, \varepsilon_{0}$ is a normalising factor and $m$ is the Weibull factor/modulus. Rearranging Equation 3 in a linear form results in:

$$
\ln \left(-\ln \left(1-P_{f}\right)\right)=m \ln \varepsilon-m \ln \varepsilon_{0}
$$

The Weibull probability of failure $\ln \left(-\ln \left(1-P_{f}\right)\right)$ is plotted against failure strain $\left(\varepsilon_{f}\right)$ for three glass thicknesses in Figure 7. The curves are fitted using a non-linear least-squares method through at least twelve repeat tests. The fitting parameters are listed in Table 2. It can be seen that the failure strain is not strongly affected by the glass thickness (e.g. considering $90 \%$ probability of failure, the failure strain is $0.81 \%$ for $2.2 \mathrm{~mm}, 0.85 \%$ for $4.0 \mathrm{~mm}$ and $0.86 \%$ for $6.0 \mathrm{~mm}$ thick glass plates). This is expected as the chemically strengthening method is a relatively thickness independent process. Note that if the linear bending theory (ASTM C 149903, 2015; British Standard, 2000) is used, it will result in significantly larger failure strain values especially for the $2.2 \mathrm{~mm}$ thick glass specimens.

\section{4- Polymer characterisation}

In this section, polymer interlayer materials used for lamination are characterised using Dynamic Mechanical Analysis (DMA) and uniaxial tensile tests spanning six orders of magnitude. The polymer interlayers were stored in dry and cool conditions and were tested within the shelf-life time of the polymers. The thermal and environmental degradation of the polymer interlayers, used in laminated glass windows, were subject of recent studies 
323 (Andreozzi et al., 2015; Kothe and Weller, 2014; Weller and Kothe, 2011). Andreozzi et al., 324 (2015) reported no significant influence on the mechanical properties of PVB with thermal

325

326

\section{4-1 Dynamic mechanical analysis}

To investigate the viscoelasticity and temperature dependency of the polymer interlayers, Dynamic Mechanical Analysis (DMA) was performed. The tests were conducted in tension mode using a TA Instruments Q800 DMA machine at the frequency of $1 \mathrm{~Hz}$ with $0.01 \mathrm{~N}$ preload and oscillation amplitude of $15 \mu \mathrm{m}$. The preload was to prevent the buckling of specimen under the oscillatory load. Strain sweep tests were performed and confirmed that all the materials remained in their viscoelastic range for the chosen amplitude. The specimens had a rectangular geometry with the width of $6.17 \mathrm{~mm}$. The thickness of the specimens was 0.76 $\mathrm{mm}$ for PVB, $1.27 \mathrm{~mm}$ for TPU and $1.52 \mathrm{~mm}$ for SGP. The free length of each specimen was measured individually after fixing the specimen in the clamp. For temperature sweep tests, the specimens were left at $-100^{\circ} \mathrm{C}$ for 10 mins, to achieve thermal equilibrium through the specimen thickness, before heating up to $80^{\circ} \mathrm{C}$ with a heating rate of $2^{\circ} \mathrm{C} \mathrm{min}^{-1}$.

When a viscoelastic material, e.g. a polymer, is subjected to an oscillating load, there will be a phase difference between the applied stress and the measured strain. This is because of the viscous component in the material response. As a result, the modulus of the material is a complex number:

$$
E=E^{\prime}+i E^{\prime \prime}
$$


where $E^{\prime}$ is the storage modulus, $E^{\prime \prime}$ ' is the loss modulus. The ratio of the storage over the loss modulus $\left(E^{\prime} / E^{\prime \prime}\right)$ is defined as tangent of the phase angle $(\operatorname{Tan} \delta)$. The results for the storage modulus, $E$ ', loss modulus, $E$ ', and tangent of the phase angle (Tan $\delta$ ) are shown in Figure 8ac. At low temperatures $\left(\mathrm{T}<-70^{\circ} \mathrm{C}\right)$, all polymer interlayers have a similar stiffness and are in their glassy state. For TPU, the transition from a glassy to rubbery state starts at the lowest temperature. This results in a significant softening in the material stiffness for temperatures above $-70^{\circ} \mathrm{C}$ (Figure $8 \mathrm{a}$ ). For the PVB and SGP polymer interlayers, the transition to the rubbery state initiates around -10 and $40{ }^{\circ} \mathrm{C}$, respectively (Figure 8a). This transition is also apparent in Figures $8 \mathrm{~b}$ and $\mathrm{c}$. In the present research, the maximum in the value of Tan $\delta$ is considered to define the glass transition temperature $\left(T_{g}\right)$ and is $-32^{\circ} \mathrm{C}$ for the TPU, $27^{\circ} \mathrm{C}$ for the PVB and $54^{\circ} \mathrm{C}$ for the SGP (Figure 8c). The difference in $T_{g}$ between the three polymers results in a significant difference in their stiffness at room temperature (i.e. the storage modulus of SGP is nearly two orders of magnitude greater than that of TPU, Figure 8a).

One major problem with the DMA technique is the limitation of frequencies and consequently strain rates that can practically be applied to the specimen. This, however, can be overcome by using the time-temperature superposition principle which suggests an equivalence between time (i.e. strain rate) and temperature on the material response. By testing a material over a limited range of frequencies, but at different temperatures, the material response can be reconstructed for a single temperature but over a wider range of frequencies. The storage modulus of the three polymer interlayers, over a frequency range spanning ten orders of magnitude, is shown in Figure 8d. The method of generating these master curves for the three polymer interlayers (i.e. TPU, PVB and SGP) is discussed in detail in (Mohagheghian et al., 2017). 


\section{4-2 Tensile tests}

370

371

372

To investigate the effect of strain rates on the large strain behaviour, uniaxial tensile tests were conducted at strain rates spanning six orders of magnitude $\left(2.38 \times 10^{-3}\right.$ to $\left.2.38 \times 10^{+2} \mathrm{~s}^{-1}\right)$. The tests at low strain rates were conducted using an Instron screw driven test machine (Instron 5800 series) whilst the high rate tests were performed using a high-speed servo-hydraulic test machine (Instron VHS 8800). Dog-bone shaped tensile specimen were cut from the polymer sheets according to the ASTM standard D412-15a (D412-15a, 2015). The specimens had a gauge length of $32 \mathrm{~mm}$ and width $6.17 \mathrm{~mm}$. The thickness of the specimens varied between the different polymers. In order to measure the local deformation inside the gauge length, the strain was measured using a video extensometer (Imetrum). The relative position of two lines marked in the gauge area of the tensile sample was monitored during the deformation of the sample. To prevent any influence from the initial inertia effects, and to have a constant nominal strain rate during the deformation, a lost motion device, similar to that described in (Hooper et al., 2012), was used. An example of the high rate tensile tests is shown in Figure 9. The tensile results for the three polymer interlayers are shown in Figure 10. Similar to the DMA results, the SGP polymer interlayer has superior mechanical properties (i.e. a higher stiffness and strength) compared to the other two polymers. At low strain rates of $2.38 \times 10^{-3} \mathrm{~s}^{-1}$ the stiffness of TPU is slightly higher than PVB. However, this quickly changes as the strain rate increases. The glass transition temperature of PVB, with a $T_{g}=27^{\circ} \mathrm{C}$, is very close to room temperature. As a result, the mechanical behaviour of PVB is very sensitive to any changes in the strain rate. Not such a strong strain rate sensitivity is observed for the TPU and SGP polymer interlayers at room temperature. Whilst the stiffness of PVB at low strain rates (e.g. $2.38 \times 10^{-3} \mathrm{~s}^{-1}$ ) is similar to that of TPU, at high strain rates (e.g. $2.38 \times 10^{+2} \mathrm{~s}^{-1}$ ) its stiffness is more comparable to the stiffness of SGP. 


\section{$394 \quad$ 5- Laminated glass}

395 In this section, the flexural bending strength of laminated glass, manufactured from the same 396 glass plates characterised in the previous section ${ }^{\dagger}$, is assessed using coaxial double ring experiment. The effect of various parameters including polymer interlayer type and thickness, glass type and multi-layering the polymer interlayer on the structural performance, as well as the fracture sequence in the glass plates, are investigated. The effect of the type of loading, e.g. concentrated versus distributed loading, are also discussed.

\section{5-1 Concentrated loading}

402

403

404

405

406

407

408

409

410

411

412

413

414

First, laminated glass plate were tested using the coaxial double ring test set up shown in Figure

2a. Owing to the strain rate sensitivity of the polymer interlayers, the experiments were conducted at a constant cross head speed of $0.5 \mathrm{~mm} \mathrm{~min}^{-1}$ (instead of a constant loading rate as used for the experiments in Section 3). In all the experiments, a thin glass plate (2.2 $\mathrm{mm}$ thick) was positioned in contact with the loading ring. No rubber gasket was used between the glass and the supporting ring. As in Section 3-1, 3D DIC was used to monitor the deformation and strain development on the surface of the back layer (i.e. of the $4.0 \mathrm{~mm}$ thick glass). The results are shown in Figure 11. Figures 11a and b show the effect of increasing the polymer interlayer thickness from $0.76 \mathrm{~mm}$ (Case 1) to $3.18 \mathrm{~mm}$ (Case 3) for a laminated glass with TPU interlayer. The initial slope of the force-displacement curves is the same for all three cases (Figure 11a). This indicates that the stiffness of the laminated glass is independent of the polymer interlayer thickness. The main difference between the three cases is the sequence of the fracture in the glass plates. For the thinner polymer interlayers (Cases 1 and 2), the fracture

\footnotetext{
${ }^{+}$With an exception of Case 4 in Table 1 for which a commercial thermally strengthened glass was employed.
} 
is initiated at the bottom glass plate (which is $4.0 \mathrm{~mm}$ thick) followed by fracture at the top layer (which is $2.2 \mathrm{~mm}$ thick). In contrast, for Case 3, the glass fractures in the top layer first. The sequence of fracture has a significant effect on the failure energy, defined as the external work needed for the failure of both glass plates. This energy, calculated by the area under the force displacement curve, is much higher in Case 3 compared to the other cases (Figure 11a). The major principal strain at the centre of the bottom plate, measured using DIC, is plotted for these cases (Cases 1-3) in Figure 11b. One notable feature here is that although in Case 3, where the specimen is fractured initially in the top layer, the strain at the centre of bottom layer is also very close to the failure strain (ca. $0.84 \%$ Table 1 ). Therefore, it is expected that for this particular loading speed, the thickness of the polymer interlayer in Case 3 is close to the limit at which the failure location changes between the two glass plates. By increasing the polymer layer thickness further the fracture is expected to always initiate from the top glass plate.

The effect of glass plate type is investigated in Figures 11c and d by comparing Cases 3 and 4 . In Case 4, instead of a chemically strengthened, a thermally strengthened glass was used for the top plate (Table 1). Thermally strengthened glass is cheaper and has a much lower strength (Gy, 2008). All other parameters are the same for these two configurations. Since the strengthening method does not change the stiffness of the material, the initial slope of the forcedisplacement curve is the same (Figure 11c). However, the top plate fractures at a lower cross head displacement (ca. $1 \mathrm{~mm}$ ) for Case 4. At this point, the major strain in the bottom glass plate only reaches $0.3 \%$ (Figure 11d). After breakage of the top glass plate in Case 3, the response of the two configurations becomes almost the same and the bottom glass plate fractures approximately at the same cross head displacement (ca. $6 \mathrm{~mm}$ ) (Figure 11c). The 437 strain at the bottom glass plate reaches the value of approximately $0.8 \%$ for both cases (Figure 438 11d) before fracture. 
439 The effect of polymer interlayer type is investigated in Figures $11 \mathrm{e}$ and $\mathrm{f}$ by comparing the 440 response of laminated glass with SGP (Case 5) and PVB (Case 6) polymer interlayers with the 441 reference case (Case 3, which has the TPU polymer interlayer). For all cases, the thickness of 442 the polymer interlayer is approximately the same (Table 1). The response of Case 6 is very 443 similar to that of Case 3. Both also have the same fracture sequence. The similarity in the bending response of the two laminates is due to the similarity in the mechanical properties of their interlayers at low strain rates (Figure 9). However, due to the strong strain rate sensitivity of PVB (Figures 8 and 10), it is expected that increasing the cross head speed would cause the stiffness Case 6 to exceed that of Case 3.

For Case 5 (the laminate with a relative stiff polymer interlayer, i.e. SGP), the slope of the force displacement curve is greater than that of both Cases 3 and 6 . As a result of the higher stiffness of the interlayer (Figure 10), more shear stress transfer between the two glass plates occurs and the response becomes more similar to that of the monolithic glass plate of equivalent thickness (Hooper, 1973). For comparison, the response of a $6 \mathrm{~mm}$ thick ${ }^{\ddagger}$ chemically strengthened glass is also plotted in Figures 11e and f. It is apparent that the stiffness of Case 5 is slightly lower than that of the monolithic glass at low rates. In contrast to Cases 3 and 6 , fracture initiates in the bottom glass plate (at the cross head displacement of about $1.8 \mathrm{~mm}$ ) followed by fracture in the top glass plate (at the cross head displacement of about $3.2 \mathrm{~mm}$ ). However, the laminated glass structure does not completely lose its load carry capacity after the second fracture (second load drop in Figure 11e). The load remains at the level of $1.3 \mathrm{kN}$ before finally the polymer interlayer (i.e. SGP) also fractures.

The effect of multi-layering the interlayer with different polymers is investigated in Figures

\footnotetext{
₹ The thickness of the plate is slightly smaller than the total thickness of the glass plates in the laminated form $(6.2 \mathrm{~mm})$.
} 
of TPU. The total thickness is nearly the same as for the only TPU (Case 3) or SGP (Case 5) polymer interlayers. For comparison, the results of Cases 3 and 5 are also included in Figures than Case 5 (only SGP present) and is only slightly greater than Case 3 (only TPU present). This is due to restriction of stress transfer between the glass plates imposed by two soft TPU layers on both sides of SGP. The fracture occurs initially in the bottom glass plate at the cross head displacement of approximately $2.2 \mathrm{~mm}$. This is followed by fracture in the top glass plate at a cross head displacement of $2.9 \mathrm{~mm}$. Similar to Case 5, the laminated glass structure retains some of its integrity and the load remains at $1.3 \mathrm{kN}$ due to the existence of the SGP layer. The structure fails at the displacement of $5.1 \mathrm{~mm}$ after the SGP layer fractured.

\section{5-2 Distributed loading}

In this section, the effect of type of loading is investigated on the fracture sequence of the laminated glass. In contrast to the previous section, for which the load is applied by a steel ring, in these tests the load is applied using a rubber cylinder attached to a flat compression platen. The rubber cylinder (silicon rubber with a Shore Hardness A of 60 from Polymax ${ }^{\circledR}$ ) had an original diameter of $14 \mathrm{~mm}$ and a length of $28 \mathrm{~mm}$. The supporting ring is the same as used in the previous section. A schematic of the set-up is shown in Figure $2 \mathrm{~b}$.

The results are plotted in Figure 12. Similar to the previous section, the effects of polymer interlayer thickness (Cases 1-2), polymer type (Cases 5 and 6), glass type (Case 4) and multilayering the interlayer (Case 7) are investigated by comparing their performance against the 
displacement. For Cases 1-3, the fracture is initiated from the bottom glass plate at a strain level of approximately $0.8 \%$ (Figures $12 \mathrm{~b}$ ) followed by fracture in the top glass plate. Small differences in the slope of the different configurations in Figure 12a are believed to be the result of small variations in the lengths of the rubber cylinders used. In Figure 13a, the central major strain is plotted against the central back deflection, measured using DIC, for Cases 1-3. Since the deformation of the rubber cylinder is excluded from the response, the major strain shows a linear relationship with displacement.

The effect of glass type is investigated in Figures 12c and d by comparing Cases 3 and 4. For Case 4, despite changing the loading type, the fracture still occurs in the top glass plate, i.e. the thermally strengthened glass plate. This causes a reduction in the peak load ( $10 \mathrm{kN}$ for Case 4 in comparison with $14.5 \mathrm{kN}$ for Case 3). The bottom glass plate fractures nearly at the same cross head displacement as the bottom glass plate of Case 3. The effect of polymer interlayer type is investigated in Figures 12e and f. Similar to Figure 11, the stiffness and the peak load are both significantly higher for Case 5. For all three types of polymer interlayers, the fracture initiates from the bottom glass plate. The central major strain is plotted against the central back deflection in Figure 13b. The response of the laminated glass with a multilayer polymer interlayer (i.e. TPU/SGP/TPU; Case 7) is compared against Case 3 (only TPU polymer interlayer) and Case 5 (only SGP polymer interlayer) in Figures $12 \mathrm{~g}$ and $\mathrm{h}$. Similar to the results that observed under concentrated loading, the response of Case 7 is very similar to that of Case 3.

\section{5-3- Discussion}


507 The polymer interlayer type and thickness, glass type as well as type of loading have a 508 significant effect on the fracture sequence of laminated glass windows. This can be especially 509 be important when safety of the laminated glass structure is critical. The external work needed 510 to fracture the glass plates, i.e. the area under the load displacement curve (Figure 11), of 511 different configurations is compared in Figure 14a for concentrated loading. The total external work is divided into the energy required to fracture the top and bottom glass plates. There is a significant difference in terms of the failure energy, i.e. the external work needed to cause failure of both glass plates, between Case 3 (i.e. the thickest polymer interlayer) compared to Cases 1 and 2. This is a consequence of the change in the fracture location from the bottom glass plate in Cases 1 and 2 to the top glass plate in Case 3. Similar values of the failure energy can be found for Cases 4 and 6, for which the fracture is also initiated in the top glass plate. For Case 5, the fracture starts in the bottom glass plate and despite having the higher stiffness and peak load, the failure energy is lower compared to Cases 3, 4 and 6. For Case 7 (a multilayer polymer interlayer), the stiffness is low (similar to Case 3) and the fracture initiates from the bottom glass plate (similar to Case 5). Both of these cause the failure energy to be lower than for both Cases 3 and 5 .

For distributed loading, the cross head displacement cannot be used to calculate the failure energy as a considerable portion of the external work is consumed in deformation of the rubber cylinder. Instead, for distributed loading, the central back deflection, measured by DIC, is used. The downside of this approach is that the energy can only be calculated up to the point of fracture in the bottom glass plate. Apart from Case 4, the fracture initiates in the bottom glass plate for all cases. However, as can be inferred from Figure 12, the amount of extra work needed to cause failure in the top plate is relatively small (less than 10\%) compared to the total work. The results are shown in Figure 14b. For distributed loading, Case 5 requires the highest amount of energy to fracture. The change in the fracture sequence for distributed loading causes 
the influence of polymer interlayer thickness on the failure energy to become less pronounced, apparent when comparing Cases 1-3. The failure energy is still highest for the laminate with the thickest polymer interlayer (Case 3).

\section{6- Low velocity soft impact response}

To assess the effect of loading rate on the sequence of fracture and failure energy, low velocity impact tests were conducted on laminated glass plates listed in Table 1. Only distributed loading is considered here.

\section{6-1 Experimental}

Low velocity impact tests were conducted using a drop tower facility. Velocities ranging from 0.5 to $3.5 \mathrm{~ms}^{-1}$ were achieved by dropping a mass of $16.9 \mathrm{~kg}$ from heights $(h)$ between 0.1 to $0.55 \mathrm{~m}$. To generate soft impact, a silicon rubber cylinder with the length of approximately 28 mm was employed, the same rubber as used for quasi-static testing in Section 5-1. The rubber cylinder was attached to a flat steel connector with the diameter of $40 \mathrm{~mm}$. The larger diameter of the steel connector is to provide support, while the deformable cylinder expands laterally. A piezoelectric sensor (PCB model 224C) was screwed to the other end of the steel connecter and was used to measure the impact load. The schematic of drop tower facility is shown in Figure 15a.

Since the load cell is located between the dropping mass and the steel connector (Figure 15a), the force measured by the load cell is not necessary the same as the force imposed by deformation of the target. A spring-mass model of the system is shown in Figure 16a, where 
$m_{1}$ and $m_{2}$ are mass of the dropping object and the steel connector respectively. Symbols $k_{1}$ and $k_{2}$ represent the stiffness of the load cell and rubber cylinder respectively. The stiffness of the load cell (PCB model 224C), $k_{l}$, has a typical value of $1.05 \times 10^{9} \mathrm{~N} \mathrm{~m}^{-1}$ (PCB Group, 2016)

557 and is significantly greater than $k_{2}$ (i.e. $k_{1} \gg k_{2}$ ). Equilibrium for $m_{1}$ (Figure 16b) requires:

$$
P(t)=-m_{1} \ddot{x}_{1}
$$

where $\ddot{x}_{1}$ is the acceleration of the mass $m_{1} . P(t)$ is the force measured by the piezoelectric 559 load cell and is equal to:

$$
P(t)=k_{1}\left(x_{1}-x_{2}\right)
$$

560 Equilibrium for $m_{2}$ (Figure 16c) requires:

$$
P(t)=k_{2}\left(x_{2}-x_{3}\right)+m_{2} \ddot{x}_{2}
$$

561

where $\ddot{x}_{2}$ is the acceleration of the mass $m_{2}$. At point A (Figure 16d):

$$
F(t)=k_{2}\left(x_{2}-x_{3}\right)
$$

where $F(t)$ is the force imposed by deformation of the target. Combining Equations 8 and 9 , 563 and normalising the two sides of equation by $F(t)$, the correction factor $C$ can be calculated by:

$$
C=\frac{F(t)}{P(t)}=1-\frac{m_{2} \ddot{x}_{2}}{P(t)}
$$

564 If $P(t)$ is replaced by Equation 6:

$$
C=1+\frac{m_{2} \ddot{x}_{2}}{m_{1} \ddot{x}_{1}}
$$

In a situation, where $k_{1}$ has a large value, $\ddot{x}_{1} \cong \ddot{x}_{2}$ and as a result, the correction factor $C$ is reduced to $1+m_{2} / m_{1}$. For the masses used in this study, $m_{1}=16.5$ and $m_{2}=0.4 \mathrm{~kg}$, this correction factor is 1.024. As the value is small, $F(t)=P(t)$ will be considered throughout the paper. In appendix, the contribution of the second term in Equation 10 is evaluated by measuring $\ddot{x}_{2}$ independently using high speed photography (i.e. without the assumption of $\ddot{x}_{1} \cong \ddot{x}_{2}$ ). The contribution is still found to be negligible. 
571 To observe damage development during the impact, two high speed cameras (Phantom Miro-

572 M310) were used. As shown in Figure 15a, one of the cameras was used for monitoring the

573 deformation and damage in the top glass plate as well as deformation of the soft cylinder. The

574 other camera was used to observe the back side of the specimen using a flat mirror oriented $45^{\circ}$

575 with respect to camera. The light was provided by halogen lamps from the top of the specimen.

576 To facilitate the observation of cracks, the bottom surface of the specimen was painted with a

577 thin white layer. An example of the image sequence captured by the two high speed cameras

578 is shown in Figure 17.

579 Laminated glass specimens with the size of $100 \times 100 \mathrm{~mm}$ were clamped to a metallic fixture

580 by using twelve M8 bolts. The clamping device had an opening with the size of $70 \times 70 \mathrm{~mm}$. To avoid any direct contact between the glass and metallic clamp, which can lead to stress concentrations at the edge of the clamping device and hence premature failure of the glass plate, rubber gaskets were used (Figure 15b). A metallic spacer (Figure 15b) was introduced to ensure a uniform and repeatable pressure in the clamped area. A two-element cross-stacked $\left(0^{\circ} / 90^{\circ}\right)$ strain gauge, FCA-5-11 from Techni Measure Ltd, was mounted on the central point of the distal (i.e. non-impacted) side of the glass plate to measure the two principal major strains

587 during impact.

Multiple impact tests were conducted on the same specimen to measure the critical impact energy for each configuration. The critical impact energy is defined here as the minimum impact energy required to break the specimen (even if only one of the two glass plates breaks). The impacts were performed from the initial height $(h)$ of $0.1 \mathrm{~m}$. The height of the drop was then gradually increased with $0.05 \mathrm{~m}$ increments (which corresponded to $8.3 \mathrm{~J}$ increments in 
terms of impact energy) up to the point of breakage. An example of the results can be found in Figure 18a, where a $6.0 \mathrm{~mm}$ thick monolithic glass plate is subjected to multiple soft impacts. The height $(h)$ of the drop was gradually increased from 0.1 to $0.55 \mathrm{~m}$ where the specimen finally broke. The absence of large contact stresses allows impacting a specimen several times without affecting its critical impact energy. Through a separate experiment, it was confirmed that the failure of the specimen is not affected by the number of impacts and the specimen only fails when the impact energy reaches its critical value. The peak force, contact time and maximum strain on the distal glass plate, measured using strain gauge, are plotted against the height of the drop $(h)$ in Figure 18b. The maximum strain and the peak force have a linear relationship with the height of the drop and consequently the impact energy. The contact time, however, is a function of the length and hardness of the rubber cylinder. A polynomial curve was fitted through the data which shows a good agreement.

\section{6-1-2 Results}

An example of test results is shown in Figure 19 where the response of three laminated glasses with different polymer interlayers: Case 3 (TPU), Case 5 (SGP) and Case 6 (PVB) are compared against a $6 \mathrm{~mm}$ thick monolithic glass plate. In Figure 19a, all the specimens are impacted from a height of $0.3 \mathrm{~m}$ (which results in an impact velocity of $2.4 \mathrm{~m} \mathrm{~s}^{-1}$ and impact energy of approximately $50 \mathrm{~J}$ ). The impact energy is not sufficient to break the glass and the impactor rebounds back. The peak force, in contrast to the contact time, is influenced by the stiffness of the target and is greatest for the monolithic glass plate and Case 5 .

Figure 19b shows an example of force traces when the impact energy is high enough to break the specimen. For most of the laminated glass specimens both glass plates virtually break at the same time (around $10 \mathrm{~ms}$ ). The fracture normally initiated in the distal glass plate and 
caused a significant load drop. After fracture of the glass plates, the response is mainly governed by the deformation of the polymer interlayer. The photographs of the failed specimens, taken from the non-impacted side, are shown in Figure 19c. The photograph of the monolithic glass plate is not shown as the specimen broke into very small pieces. Failure is very similar for Cases 3 and 6: radial and circumferential cracks in both glass plates while the whole structure is still intact. For these cases, only the glass fragments on a small area at the centre of the plate are detached. The number of detached fragments is significantly greater for Case 5. The polymer interlayer is also ruptured and the whole plate fractured into four large pieces.

The critical impact breakage energy is compared in Figure 20 for eight different configurations. The values are the average of five repeat tests while the error bars indicate the variation in each case. As discussed earlier, the critical impact breakage energy here is the minimum energy that can cause fracture in one or both of the glass plates. For most specimens, fractures normally initiated from the distal (non-impacted) glass plate. The only exception was Case 4, in which the failure occurred in the impacted glass plate (i.e. in the thermally strengthened glass plate). Similar to the quasi-static results for distributed loading in Figure 14b, changing the polymer interlayer thickness from $0.76 \mathrm{~mm}$ (Case 1) to $1.27 \mathrm{~mm}$ (Case 2) has no significant effect on the critical impact energy (Figure 20). A further increase in the polymer interlayer thickness to $3.18 \mathrm{~mm}$ (Case 3) causes a modest increase in the critical impact energy. The polymer interlayer type has the strongest influence on the performance, and the impact breakage energy is highest, for Case 5 (i.e. the SGP interlayer). Case 6 (i.e. the PVB interlayer) shows better impact performance than Case 3 (i.e. the TPU interlayer) under low velocity impact loading. The peak force obtained under quasi-static and impact loadings are compared in Figure 21 for different laminated glass configurations (i.e. Cases 1 to 7 ). Since the boundary condition is different for the two cases, a direct comparison between quasi-static and impact values is not 
644

645

646

647

648

649

650

651

652

653

654

655

656

657

658

659

660

661

663

664

665

possible. The aim here is, however, to compare the relative performance of the various cases under quasi-static and impact loading. The largest increase in the peak force is observed for the PVB interlayer. This improvement under impact loading can be attributed to the strong strain rate sensitivity of the PVB, as observed in Figure 8d and Figure 10.

\section{6-2 Numerical modelling}

The finite element method is used to simulate the response of the laminated glass windows subjected to low velocity soft impact. The simulations were performed using Abaqus/explicit. As a result of symmetry, only one quarter of the target was modelled (Figure 22) with a symmetry boundary condition applied along the sectioned surfaces. The boundary conditions in Figure $15 \mathrm{~b}$ are modelled including the two rubber gaskets. The top surface of the upper and the bottom surface of the lower gaskets are constrained in the $z$ direction, simulating the presence of the two clamps in Figure 15b. The target including glass, polymer interlayer and rubber gaskets were discretised using brick elements with eight nodes and reduced integration, C3D8R (in Abaqus notation). The glass plates were modelled as elastic materials with $\rho=2440$ $\mathrm{kg} \mathrm{m}^{-3}, E=71.7 \mathrm{GPa}$ and $v=0.21$ (Xue et al., 2013) where $\rho, E$ and $v$ are the density, elastic modulus and Poisson's ratio respectively. The rubber impactor was modelled using a hyperelastic material model (Neo-Hookean) with a strain energy density function $W$ of:

$$
W=C_{1}\left(I_{1}-3\right),
$$

where $C_{1}$ is a material parameter and $I_{1}$ is the first invariant of the right Cauchy-Green deformation tensor. For silicon rubber used here, a Shore Hardness A of $60, C_{l}=0.9 \mathrm{MPa}$ (Heimbs et al., 2011) was used. For the rubber gaskets, the same hyperelastic model with $C_{1}=$ 2 MPa for a Shore Hardness A of 80 (Heimbs et al., 2011) was used. The density of $1060 \mathrm{~kg}$ 
$666 \mathrm{~m}^{-3}$ was considered for both rubbers. To prevent self-buckling under compression, a slight 667 curvature was introduced to the outer surface of the rubber cylinder, as shown in Figure 22. 668 For the polymer interlayers, a linear viscoelastic material model (i.e. a generalised Maxwell 669 model) was chosen as follows:

$$
E(t)=E_{\infty}+\sum_{i=1}^{n} E_{i} e^{-\left(\frac{t}{\tau_{i}}\right)},
$$

670

where $E_{\infty}$ is the long-term modulus and $E_{i}$ is elastic modulus associated to the relaxation time $\tau_{i}$. Material parameters for Equation 13 were extracted with a method similar to that adopted by Macaloney et al (2007). The viscoelastic model is fitted through the data in the frequency domain (master curves for the three polymer interlayers in Figure 8d) using:

$$
E^{\prime}(\omega)=E_{\infty}+\sum_{i=1}^{n} \frac{\omega^{2} \tau_{i}^{2} E_{i}}{\omega^{2} \tau_{i}^{2}+1}
$$

The data were fitted using a non-linear least-squares method. It was found that twelve Maxwell elements (i.e. $n=12$ ) were enough to accurately represent the response over the interested frequency range. The fitting parameters used for the three polymer interlayers in Abaqus are listed in Table 3. The parameters are in the form of shear modulus $\left(G_{i}\right)$, which their values are calculated based on the incompressibility assumption by $G_{i}=E_{i} / 3$. The same approach was adopted by Hooper et al. (2012). The result of fitting for the three polymer interlayer is shown in Figure 8d. Densities of 1070, 1100 and $950 \mathrm{~kg} \mathrm{~m}^{-3}$ were used in the FE model for TPU, PVB and SGP interlayers respectively.

An example of the simulation results is shown in Figure 23. Deformation of the soft rubber cylinder, as well as the maximum principal stress in the laminated glass, are shown up to the point of maximum deflection at $t=15 \mathrm{~ms}$. The comparison between the numerical and experimental results is shown in Figure 24 for monolithic glass as well as the laminated glass 
specimen with three different polymer interlayers. The comparison is made for the peak force and central strain at the back surface of the distal glass plate. The impact conditions were the same in all cases (i.e. a drop height of $h=0.2 \mathrm{~m}$ ). Good agreement between the numerical and experimental results can be seen in Figure 24 for all the various specimens, especially in the loading phase.

The effect of the thickness of the polymer interlayer $\left(h_{p}\right)$ on strain development in the glass plates are numerically investigated in Figure 25. The simulations were performed for a laminated glass with a TPU interlayer for which the $h_{p}$ changes from 0.76 to $5.0 \mathrm{~mm}$. For $h_{p}=$ 0.76 and $1.27 \mathrm{~mm}$, the strain values at the distal glass plate (location 2 as defined in Figure 25) are twice as large as that of the impacted glass plate (Location 1). The difference in the strain values is negligible between the two polymer interlayer thicknesses. This explains why no difference was observed between the impact energy breakage of Cases 1 and 2 in Figure 20. By increasing the value of $h_{p}$ further, strain values at the Location 2 are decreased slightly and as a result a higher impact energy is needed to cause fracture (as observed for Case 3 in Figure 20). The strain values in Location 1 , however, increase by increasing $h_{p}$ with a rate that is significantly higher than the rate of decrease in strain value in Location 2 . At $h_{p}=5.0 \mathrm{~mm}$, the maximum strain at Locations 1 and 2 becomes similar and the location of fracture initiation can switch from Location 2 to Location 1.

\section{7- Conclusions}

In this paper, the quasi-static bending as well as the low velocity impact performance of monolithic and laminated glass windows made of chemically strengthened glass were evaluated. A coaxial double ring experiment in combination with a 3D Digital Image 
709 Correlation technique was employed to experimentally measure the quasi-static flexural strength of 2.2, 4.0 and $6.0 \mathrm{~mm}$ thick chemically strengthened glass plates, both in a monolithic form and as laminated glass structures. Through a systematic study, the effect of various design parameters including polymer interlayer thickness, glass and polymer type and multi-layering the polymer interlayer on the quasi-static bending and low velocity impact performance of laminated glass plates were studied. Both localised and distributed loadings were considered for quasi-static evaluation. The following conclusions are drawn:

- Conventional test methods (BS EN1288-5 and ASTM C 1499), which are based on linear bending theory, were found to be inadequate for characterising the strength of due to large deformation of the glass plates during bending and consequently the development of membrane stresses.

- A 3D digital image correlation technique was successfully employed to measure experimentally the failure strain of the specimens, as well as monitoring the full-field displacement and strain development throughout the deformation. This optical noncontact technique does not have the limitations of the conventional strain measurements (e.g. using strain gauge) and can conveniently be used when a large number of experiments are needed (e.g. for glass characterisation).

- The type of loading has a significant influence on the fracture sequence in the glass plates. For distributed loading, in the absence of contact stresses and concentrated deformation, the fracture initiation location was moved to the bottom glass plate for most laminated glass configurations used in this study.

- Increasing the polymer interlayer thickness in the laminated glass configurations has no significant effect on the stiffness of the structure. However, it has a notable influence on the fracture sequence and consequently the post-fracture safety of the laminated 
glass structure. Increasing the polymer interlayer thickness causes a change in the fracture initiation location and an increase in the failure energy.

- The polymer interlayer type has the strongest effect on the stiffness and strength of laminated glass plates. Laminates with the stiffest polymer interlayer (i.e. the SGP polymer interlayer) exhibit the highest stiffness and strength. This is because of better shear transfer between the two glass plates.

- Multi-layering the interlayer e.g. sandwiching a stiff SGP between two layers of soft TPU is often used for aerospace applications and does not provide any significant structural advantages. This is due to the restriction of shear stress transferring between and other applications. 


\section{Acknowledgement}

760 Much appreciated is the strong support received from AVIC Beijing Institute of Aeronautical

761 Materials (BIAM). The research was performed at the AVIC Centre for Materials

762 Characterisation, Processing and Modelling at Imperial College London. The authors are very

763 grateful for the thoughtful discussions with Professor John Field FRS at the Cavendish

764 Laboratory, Dr Stephen Walley at the Cavendish Laboratory, Professor Gordon Williams FRS,

765 Professor Peter Cawley FRS and Professor Jianguo Lin FREng of Imperial College London.

766 


\section{Appendix}

768 In this section, the validity of the assumption $C \cong 1$ is assessed by measuring the deceleration

769 of the mass $m_{2}$ independently using high speed photography. For this purpose, the edge of the

770 steel connector (as shown in Figure 17) was tracked through image sequences. An example of

771 the results is shown in Figure A-1 for a laminated glass with SGP interlayer impacted from a

772 height of $0.5 \mathrm{~m}$. Velocity of $m_{2}$ is then calculated by differentiating displacement, measured

773 using high speed photography, against time,. Similarly, the acceleration is calculated by

774 differentiating the velocity against time. As a result of differentiation, errors in the

775 displacement measurements are magnified. To reduce the noise, a filter was applied through

776 the data points for velocity and acceleration (Figure A-1). In Figure A-2, the force measured

777 by piezoelectric load cell $P(t)$ is compared against $m_{2} \ddot{x}_{2}$. As can be seen, the latter has a

778 negligible contribution and $C$ can be considered equal to one. 
781 Figure 1: Experimental test set up: (a) photograph and (b) schematic of biaxial flexural testing 782 rig and (c arrangements used for 3D digital image correlation (DIC) measurements.

783 Figure 2: Two types of loading used: (a) concentrated and (b) distributed.

784 Figure 3: Comparison between strain measurements using 3D DIC and strain gauge for 2.2, 4.0 and $6.0 \mathrm{~mm}$ chemically strengthened glass plates. The measurements were performed at the centre of the plate.

787 Figure 4: Full-field (a) out-of-plane displacement and (b) major principal strain contours for 2.2, 4.0 and $6.0 \mathrm{~mm}$ chemically strengthened glass plates, measured during coaxial double ring tests.

Figure 5: Coaxial double ring test results for a $2.2 \mathrm{~mm}$ chemically strengthened glass: (a) force against cross head displacement measured using Instron, (b) out-of-plane displacement and (c) major principal strain profile measured using DIC.

Figure 6: Force against cross head displacement for a (a) 2.2, (b) 4.0 and (c) $6.0 \mathrm{~mm}$ thick chemically strengthened glass. The experimental curves are compared with theoretical linear curves predicted by linear bending theory.

Figure 7: Weibull probability plots for failure of 2.2, 4.0 and $6.0 \mathrm{~mm}$ thick chemically strengthened glasses under biaxial loading.

Figure 8: Dynamic mechanical analysis results: (a) storage modulus $\left(E^{\prime}\right)$, (b) loss modulus $\left(E^{\prime}\right.$ '), (c) tangent of the phase angle (Tan $\delta$ ) plotted against temperature for the thermoplastic polyurethane (TPU), polyvinyl butyral (PVB) and ionoplast SentryGlas ${ }^{\circledR}$ Plus (SGP) polymer 
interlayers and (d) shows storage modulus against frequency at $25^{\circ} \mathrm{C}$ with results from the fitted generalised Maxwell model.

Figure 9: An example of the results from a high rate tensile test for the SGP polymer interlayer at a cross head speed of $0.83 \mathrm{~m} \mathrm{~s}^{-1}$.

Figure 10: Uniaxial tensile response of (a) thermoplastic polyurethane (TPU), (b) polyvinyl butyral (PVB) and (c) ionoplast SentryGlas ${ }^{\circledR}$ Plus (SGP) polymer interlayers at strain rates ranging from $2.38 \times 10^{-3}$ to $2.38 \times 10^{+2} \mathrm{~s}^{-1}$.

Figure 11: Flexural response of laminated glass plates of various configurations using concentrated loading (coaxial double ring) investigating the effect of: (a and b) polymer interlayer thickness using 0.76, 1.27 and $3.18 \mathrm{~mm}$ TPU, (c and d) glass type, comparing thermally and chemically glass plates, ( $\mathrm{d}$ and e) polymer interlayer type, using thermoplastic polyurethane (TPU), polyvinyl butyral (PVB) and ionoplast SentryGlas ${ }^{\circledR}$ Plus (SGP) and (g and h) multi-layering the interlayer, using a TPU/SGP/TPU multilayer. The central major principal strain was measured using 3D DIC from the back side of the distal glass plate (4.0 mm thick). (See Table 1 for the definition of the various Cases.)

Figure 12: Flexural response of laminated glass plates of various configurations using 817 distributed loading investigating the effect of: (a and b) polymer interlayer thickness, using 0.76, 1.27 and $3.18 \mathrm{~mm}$ TPU, (c and d) glass type, comparing thermally and chemically glass 819 plate, (d and e) polymer interlayer type ,using thermoplastic polyurethane (TPU), polyvinyl 820 butyral (PVB) and ionoplast SentryGlas ${ }^{\circledR}$ Plus (SGP) and (g and h) multi-layering the interlayer, using TPU/SGP/TPU multilayer. The central major principal strain was measured using 3D DIC from the back side of distal glass plate (4.0 mm thick). 
823 Figure 13: Comparison between flexural response of laminated glass plates with various 824 polymer interlayer (a) thickness and (b) type using central back face deflection measured using 825 DIC.

826 Figure 14: Comparison between failure energy of laminated glass plates of various 827 configurations for (a) concentrated and (b) distributed loadings. "T" and "B" represent the 828 failure in the top and bottom glass plates respectively.

829 Figure 15: Schematic of (a) drop tower test set up and (b) clamping arrangement for the test 830 specimen.

Figure 16: Drop tower test set up: (a) spring-mass model and (b) free body diagrams of various components.

Figure 17: High speed image sequences showing the deformation of the soft impactor (top row) and damage development in the laminated glass sample (bottom row) subjected to low velocity soft impact. Time, $t=0$, represents the moment of initial contact between the impactor and the target.

837 Figure 18: Low velocity soft impact results for a $6.0 \mathrm{~mm}$ thick chemically strengthened glass plate. (a) shows force traces resulting from incremental increase in impact energy up to the 839 point of fracture. (b) peak force, maximum strain, measured using a strain gauge, and contact 840 time against the drop height $(h)$.

841 Figure 19: Comparison between impact force traces resulting from low velocity soft impact of 842 laminated glass with TPU, PVB and SGP interlayers as well as a $6.0 \mathrm{~mm}$ monolithic glass for (a) an identical drop height of $0.3 \mathrm{~m}$ and (b) at the point of breakage (different drop heights). (c) shows the photograph taken from non-impacted side of the failed laminated glass specimens.

845 Figure 20: Impact breakage energy of various configurations 
846 Figure 21: Comparison between peak forces of various configurations obtained under quasi-

847 static and impact loadings.

848 Figure 22: 3D finite element model of low velocity soft impact.

849 Figure 23: Example of finite element simulations for a laminated glass with TPU interlayer 850 (Case 3) impacted from a drop height of $0.2 \mathrm{~m}$ (impact velocity of $1.98 \mathrm{~m} \mathrm{~s}^{-1}$ ).

851 Figure 24: Comparison between experimental and numerical results for (a) a $6.0 \mathrm{~mm}$ thick 852 monolithic glass and laminated glass plates with (b) TPU (Case 3), (c) SGP (Case 5) and (d) 853 PVB (Case 6) interlayers. The comparison is made for peak force and strain at the central 854 location of distal glass plate for an impact from a height of $0.2 \mathrm{~m}$ (impact velocity of $\left.8551.98 \mathrm{~m} \mathrm{~s}^{-1}\right)$.

856 Figure 25: The effect of increasing polymer interlayer thickness on the strain development in 857 the glass plates. The simulations were performed for a laminated glass with a TPU interlayer 858 (Case 3) impacted from a drop height of $0.2 \mathrm{~m}$ (impact velocity of $1.98 \mathrm{~m} \mathrm{~s}^{-1}$ ).

859 Figure A-1: Measurement of (a) displacement and velocity, and (b) acceleration of the steel 860 connector (mass $m_{2}$ ) using high speed photography. The results are for a laminated glass 861 specimen with SGP interlayer (Case 5) impacted from a height of $0.5 \mathrm{~m}$. Solid lines are smooth 862 curves which are fitted through the data.

863 Figure A-2: Comparison between force measured using piezoelectric load cell, $P(t)$, and inertia 864 force of the steel connector, $m_{2} \ddot{x}_{2}$. 


\section{References}

867

868

869

870

871

872

873

874

875

876

877

878

879

880

881

882

883

884

885

886

887

888

889

890

891

892

893

894

895

896

897

898

899

900

901

902

903

904

905

906

Andreozzi, L., Briccoli Bati, S., Fagone, M., Ranocchiai, G., Zulli, F., 2015. Weathering action on thermo-viscoelastic properties of polymer interlayers for laminated glass. Constr. Build. Mater. 98, 757-766. doi:10.1016/j.conbuildmat.2015.08.010

ASTM C 1499-03, 2015. Standard Test Method for Monotonic Equibiaxial Flexural Strength of Advanced Ceramics at Ambient Temperature 1. ASTM Stand. 1, 1-13. doi:10.1520/C1499-09

Backman, M.E., Goldsmith, W., 1978. The mechanics of penetration of projectiles into targets. Int. J. Eng. Sci. 16, 1-99. doi:10.1016/0020-7225(78)90002-2

Behr, R.A., Kremer, P.A., Dharani, L.R., Ji, F.S., Kaiser, N.D., 1999. Dynamic strains in architectural laminated glass subjected to low velocity impacts from small projectiles. J. Mater. Sci. 34, 5749-5756. doi:10.1023/A:1004702100357

Behr, R.A., Minor, J.E., Linden, M.P., 1986. Load Duration and Interlayer Thickness Effects on Laminated Glass. J. Struct. Eng. 112, 1441-1453. doi:10.1061/(ASCE)07339445(1986)112:6(1441)

Behr, R.A., Minor, J.E., Norville, H.S., 1993. Structural Behavior of Architectural Laminated Glass. J. Struct. Eng. 119, 202-222. doi:10.1061/(ASCE)0733-9445(1993)119:1(202)

Belis, J., Depauw, J., Callewaert, D., 2009. Failure mechanisms and residual capacity of annealed glass/SGP laminated beams at room temperature. Eng. Fail. Anal. 16, 18661875. doi:10.1016/j.engfailanal.2008.09.023

Bennison, S., Qin, M., Davies, P., 2008. High-performance laminated glass for structurally efficient glazing, in: Innovative Light-Weight Structures and Sustainable Facades. pp. $1-12$.

Bennison, S.J., Jagota, A., Smith, C.A., 1999. Fracture of Glass/Poly(vinyl butyral) (Butacite®) Laminates in Biaxial Flexure. J. Am. Ceram. Soc. 82, 1761-1770. doi:10.1111/j.1151-2916.1999.tb01997.x

Bennison, S.J., Smith, C.A., Van Duser, A., Jagota, A., 2001. Structural Performance of Laminated Glass Made with a "Stiff” Interlayer. Glas. Process. Days 2001 283-287.

British Standard, 2000. EN 1288-5 Glass in Building - Determination of the Bending Strength of Glass - Part 5: Coaxial Ring Tests on Flat Specimens with Small Surface Areas.

Connolly, D., Stockton, A.C., O’Sullivan, T.C., 1989. Large-Deformation Strength Analysis of Chemically Strengthened Glass Disks. J. Am. Ceram. Soc. 72, 859-863. doi:10.1111/j.1151-2916.1989.tb06234.x

D412-15a, 2015. Standard Test Methods for Vulcanized Rubber and Thermoplastic Elastomers - Tension. Annu. B. ASTM Stand. 1-14. doi:10.1520/D0412-06AE02.2

Dharani, L.R., Yu, J., 2004. Failure modes of glass panels subjected to soft missile impact. Damage Fract. Mech. VIII WIT p, 163-171. doi:10.2495/DF040171

Flocker, F.W., Dharani, L.R., 1998. Low Velocity Impact Resistance of Laminated Architectural Glass. J. Archit. Eng. 4, 12-17. doi:10.1061/(ASCE)10760431(1998)4:1(12) 
Grant, P.., Cantwell, W.., McKenzie, H., Corkhill, P., 1998. the Damage Threshold of Laminated Glass Structures. Int. J. Impact Eng. 21, 737-746. doi:10.1016/S0734743X(98)00027-X

Gulati, S.T., Helfinstine, J.D., Roe, T.A., Hillman, M.L., Lapp, J.C., 2002. 6.2: Biaxial Strength of Ultrathin AMLCD Glass Substrates. SID Symp. Dig. Tech. Pap. 33, 49. doi:10.1889/1.1830842

Gy, R., 2008. Ion exchange for glass strengthening. Mater. Sci. Eng. B 149, 159-165. doi:10.1016/j.mseb.2007.11.029

Hale, D.K., 1968. Strengthening of Silicate Glasses by Ion Exchange. Nature 217, 11151118. doi:10.1038/2171115a0

Heimbs, S., Van Den Broucke, B., Duplessis Kergomard, Y., Dau, F., Malherbe, B., 2011. Rubber Impact on 3D Textile Composites. Appl. Compos. Mater. 19, 275-295. doi:10.1007/s10443-011-9205-z

Hooper, J.A., 1973. On the bending of architectural laminated glass. Int. J. Mech. Sci. 15, 309-323. doi:10.1016/0020-7403(73)90012-X

Hooper, P.A., Blackman, B.R.K., Dear, J.P., 2012. The mechanical behaviour of poly(vinyl butyral) at different strain magnitudes and strain rates. J. Mater. Sci. 47, 3564-3576. doi:10.1007/s10853-011-6202-4

Inoue, M., Takizawa, Y., Okada, A., 1991. Non-linear flexure testing of a high-strength glass disk. Int. J. Solids Struct. 28, 1185-1197. doi:10.1016/0020-7683(91)90111-R

Jain, R., Lock, J., Duffy, S.F., 2009. Effective Area and Effective Volume Calculations for Ceramic Test Specimens, in: Volume 1: Aircraft Engine; Ceramics; Coal, Biomass and Alternative Fuels; Controls, Diagnostics and Instrumentation; Education; Electric Power; Awards and Honors. ASME, pp. 231-239. doi:10.1115/GT2009-59028

Ji, F.S., Dharani, L.R., 1998. Damage probability in laminated glass subjected to low velocity small missile impacts 3, 4775-4782.

Jiang, L., Wang, Y., Mohagheghian, I., Li, X., Guo, X., 2017. Effect of residual stress on the fracture of chemically strengthened thin aluminasilicate glass. J. Mater. Sci. 52, 14051415. doi:10.1007/s10853-016-0434-2

Kaiser, N.D., Behr, R.A., Minor, J.E., Dharani, L.R., Ji, F., Kremer, P.A., 2000. Impact Resistance of Laminated Glass Using "Sacrificial Ply" Design Concept. J. Archit. Eng. 6, 24-34. doi:10.1061/(ASCE)1076-0431(2000)6:1(24)

Kao, R., Perrone, N., Capps, W., 1971. Large-Deflection Solution of the Coaxial-RingCircular-Glass-Plate Flexure Problem. J. Am. Ceram. Soc. 54, 566-571. doi:10.1111/j.1151-2916.1971.tb12209.x

Kistler, S.S., 1962. Stresses in glass produced by nonuniform exchange of monovalent ions. J. Am. Ceram. Soc. 45, 59-68. doi:10.1111/j.1151-2916.1962.tb11081.x

Kondo, S., Katoh, Y., Kim, J.W., Snead, L.L., 2014. Validation of Ring-on-Ring Flexural Test for Nuclear Ceramics Using Miniaturized Specimens, in: Igarss 2014. pp. 83-92. doi:10.1002/9780470584002.ch8

Kothe, M., Weller, B., 2014. Influence of environmental stresses to the ageing behaviour of interlayer, in: Challenging Glass 4 \& COST Action TU0905 Final Conference. CRC 
Li, X., Jiang, L., Zhang, X., Yan, Y., 2014. Influence of residual compressive stress on nanoindentation response of ion-exchanged aluminosilicate float glass on air and tin sides. J. Non. Cryst. Solids 385, 1-8. doi:10.1016/j.jnoncrysol.2013.10.018

Macaloney, N., Bujanda, A., Jensen, R., Goulbourne, N., 2007. Viscoelastic Characterization of Aliphatic Polyurethane Interlayers. Army Res. Lab. Reprt No:, ARL-TR-4296.

Mohagheghian, I., Wang, Y., Zhou, J., Guo, X., Jiang, L., Zhang, X., Yan, Y., Charalambides, M.N., Dear, J.P., 2017. Effect of polymer interlayer on high velocity soft impact response of laminated glass plates.

Overend, M., Butchart, C., Lambert, H., Prassas, M., 2014. The mechanical performance of laminated hybrid-glass units. Compos. Struct. 110, 163-173. doi:10.1016/j.compstruct.2013.11.009

Pacios, A., Postigo, S., Huerta, C., 2011. Relationship between characteristic parameters of impact test for safety glasses. Stahlbau 61-66. doi:10.1002/stab.201120008

PCB Group, 2016. http://www.pcb.com/Products.aspx?m=224C [WWW Document]. PCB Gr.

Pyttel, T., Liebertz, H., Cai, J., 2011. Failure criterion for laminated glass under impact loading and its application in finite element simulation. Int. J. Impact Eng. 38, 252-263. doi:10.1016/j.ijimpeng.2010.10.035

Ritter, J.E., Jakus, K., Batakis, A., Bandyopadhyay, N., 1980. Appraisal of biaxial strength testing. J. Non. Cryst. Solids 38-39, 419-424. doi:10.1016/0022-3093(80)90455-X

Saxe, T.J., Behr, R. a., Minor, J.E., Kremer, P. a., Dharani, L.R., 2002. Effects of Missile Size and Glass Type on Impact Resistance of "Sacrificial Ply" Laminated Glass. J. Archit. Eng. 8, 24-39. doi:10.1061/(ASCE)1076-0431(2002)8:1(24)

Schreier, H., Orteu, J.-J., Sutton, M. a., 2009. Image Correlation for Shape, Motion and Deformation Measurements. Springer. doi:10.1007/978-0-387-78747-3

Shetty, M.S., Dharani, L.R., Stutts, D.S., 2012. Analysis of Laminated Architectural Glazing Subjected to Wind Load and Windborne Debris Impact. ISRN Civ. Eng. 2012, 1-9. doi:10.5402/2012/949070

Untaroiu, C.D., Shin, J., Crandall, J.R., 2007. A design optimization approach of vehicle hood for pedestrian protection. Int. J. Crashworthiness 12, 581-589. doi:10.1080/13588260701492947

Varshneya, A.K., 2010. Chemical Strengthening of Glass: Lessons Learned and Yet To Be Learned. Int. J. Appl. Glas. Sci. 1, 131-142. doi:10.1111/j.2041-1294.2010.00010.x

Vepakomma, K.H., Westbrook, J., Carley, S., Jum Kim, 2013. Finite Element Analysis of Ring-on-Ring Test on LCD Panels. J. Disp. Technol. 9, 673-677. doi:10.1109/JDT.2013.2251744

Vitman, F.F., Bartenev, G.M., Pukh, V.P., Tsepkov, L.P., 1963. A method for measuring the strength of sheet glass. Glas. Ceram. 19, 412-414. doi:10.1007/BF00681213

Walley, S.M., Field, J.E., Blair, P.W., Milford, a. J., 2004. The effect of temperature on the impact behaviour of glass/polycarbonate laminates. Int. J. Impact Eng. 30, 31-53. doi:10.1016/S0734-743X(03)00046-0 
1007
Weller, P.B., Kothe, D.M., 2011. Ageing Behaviour of Polymeric Interlayer Materials and Laminates. Glas. Perform. Days 2011 240-243.

Wilcox, D.I., Akarapu, R.K., Gulati, S.T., Widjaja, S., Antimonov, M., 2013. Biaxial stress in thin glass during ring-on-ring testing with large deflections. Dig. Tech. Pap. - SID Int. Symp. 44, 874-876. doi:10.1002/j.2168-0159.2013.tb06358.x

Xue, L., Coble, C.R., Lee, H., Yu, D., Chaparala, S., Park, S., 2013. Dynamic Analysis of Thin Glass Under Ball Drop Impact With New Metrics, in: Volume 1: Advanced Packaging; Emerging Technologies; Modeling and Simulation; Multi-Physics Based Reliability; MEMS and NEMS; Materials and Processes. ASME, p. V001T03A006. doi:10.1115/IPACK2013-73291

Zhang, X., Hao, H., Ma, G., 2013. Laboratory test and numerical simulation of laminated glass window vulnerability to debris impact. Int. J. Impact Eng. 55, 49-62. doi:10.1016/j.ijimpeng.2013.01.002

Zhao, S., Dharani, L.R., Chai, L., Barbat, S.D., 2006. Analysis of damage in laminated automotive glazing subjected to simulated head impact. Eng. Fail. Anal. 13, 582-597. doi:10.1016/j.engfailanal.2004.12.038 
1009 Figure 1:

1010

(a)

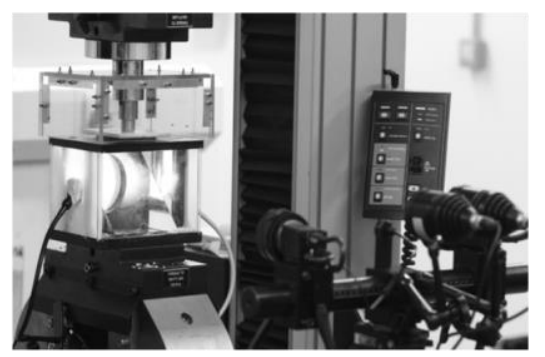

(c)

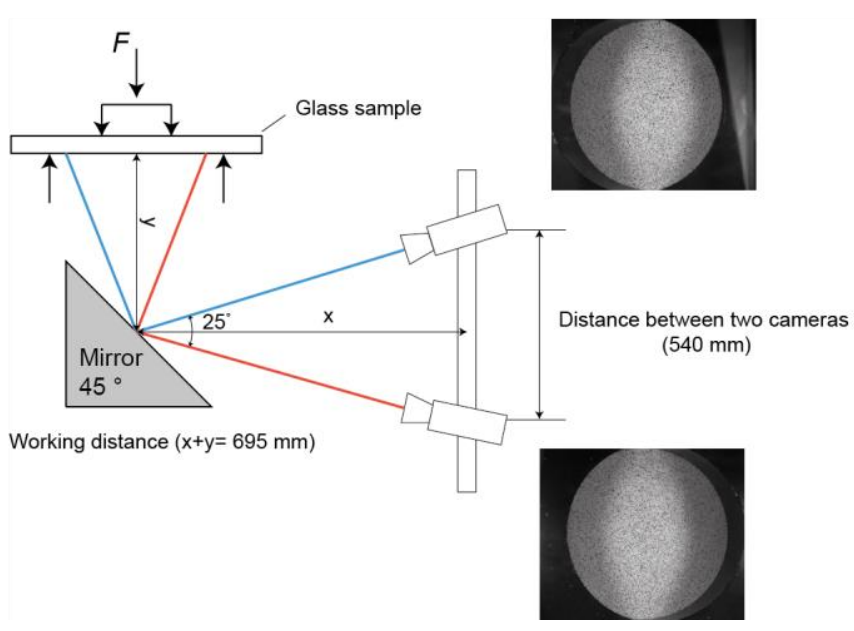

1012

1013 
1014 Figure 2:

1015

(a)

Concentrated loading

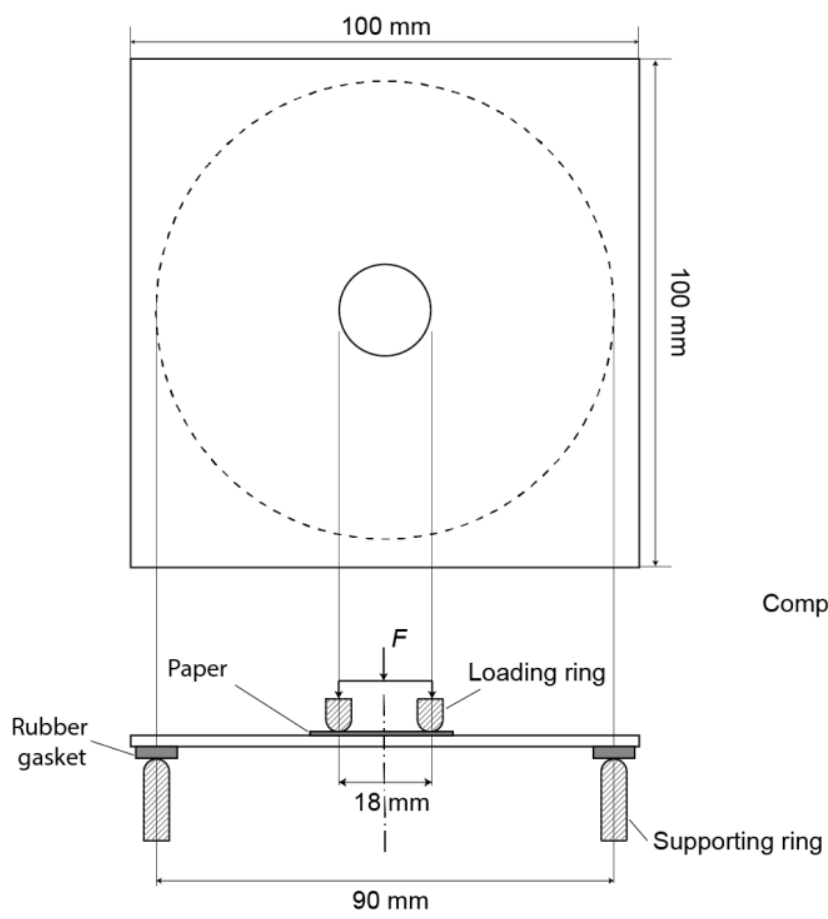

(b)

\section{Distributed loading}

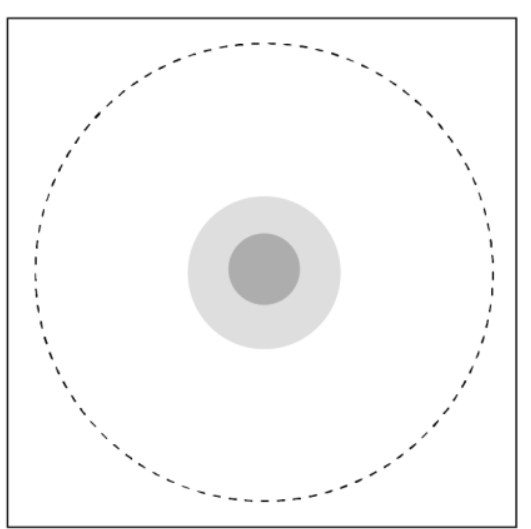

compression platen

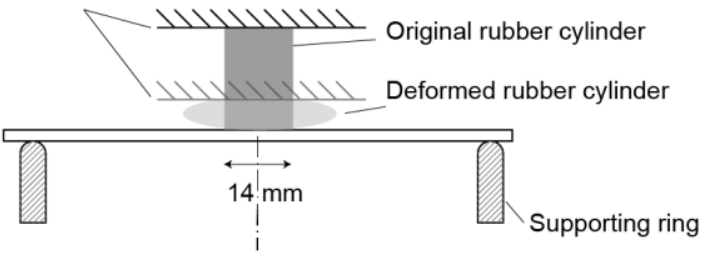

1016

1017 
1018 Figure 3:

1019
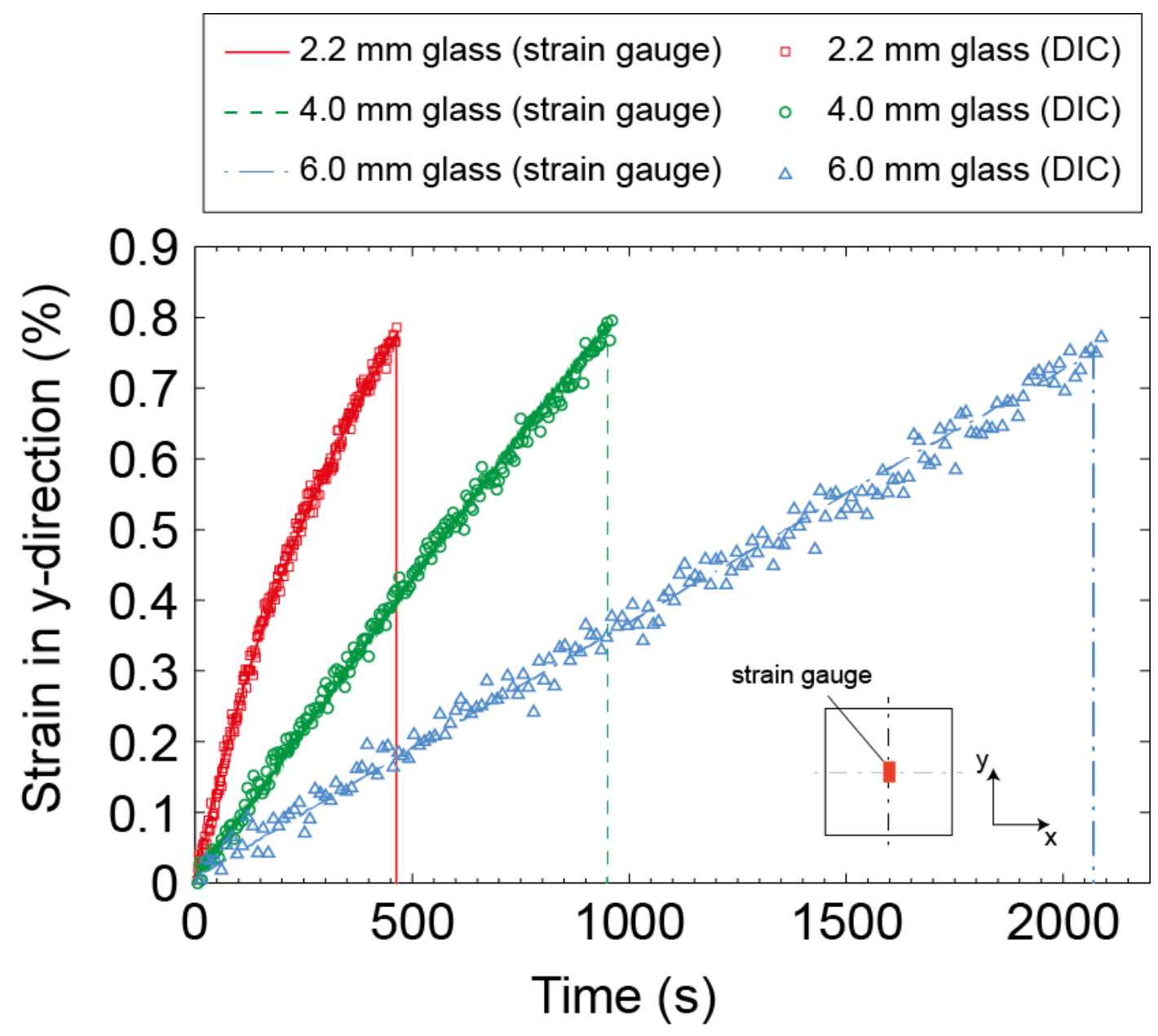

1021

1022 
1023 Figure 4:

1024

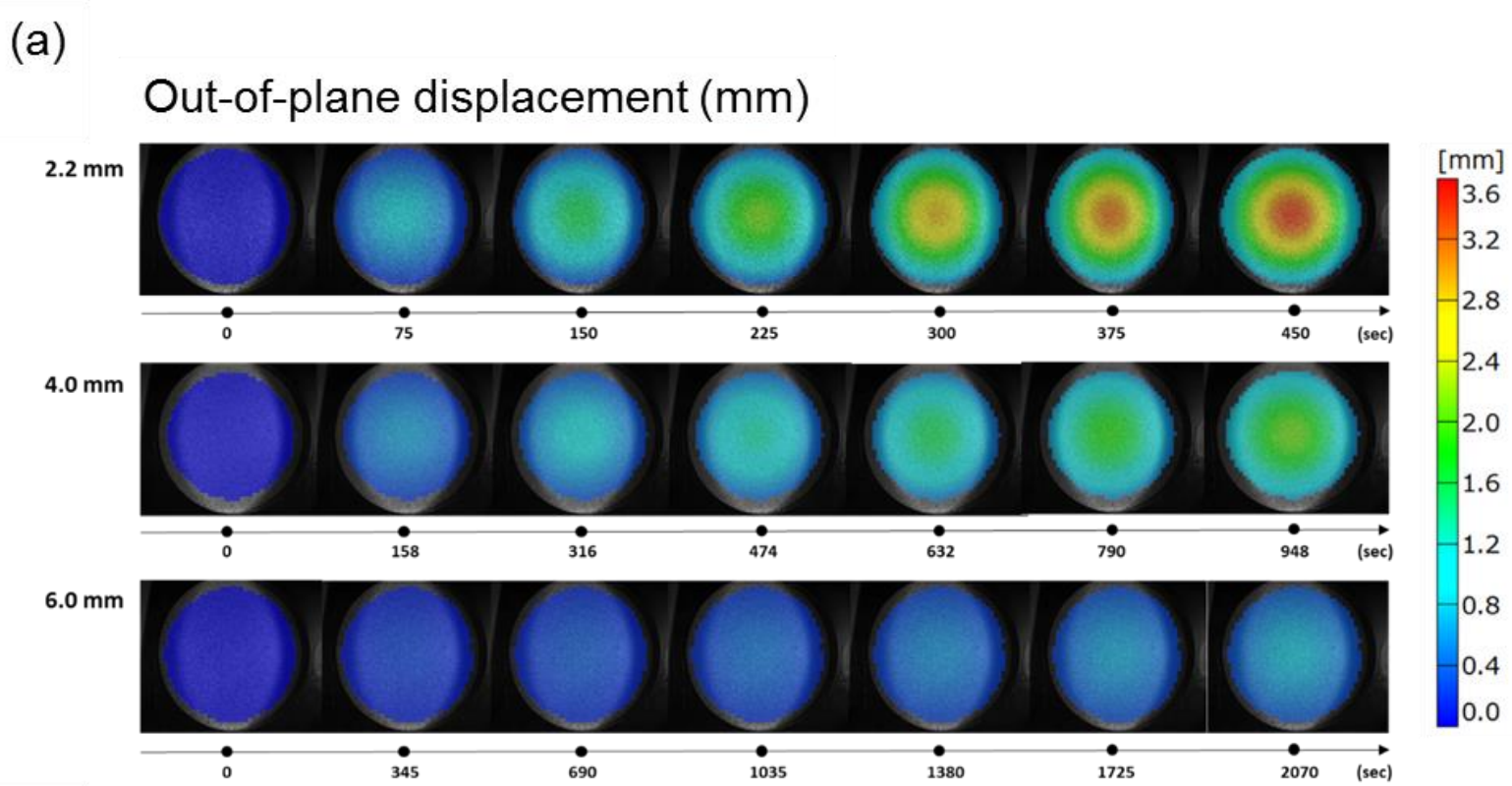

(b)
Major principal strain (\%)

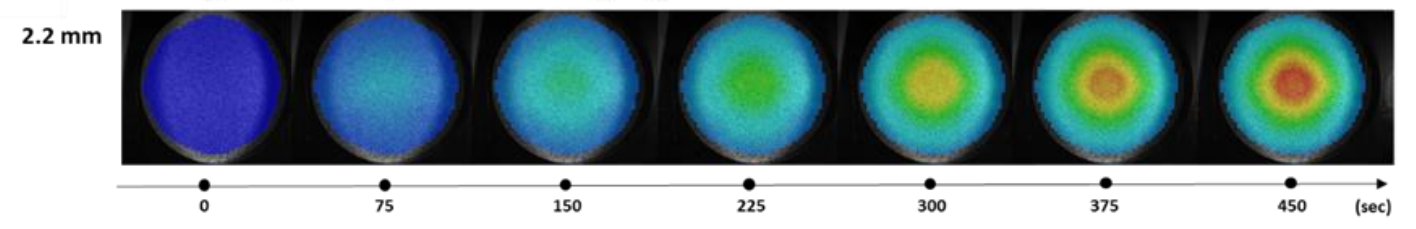

$4.0 \mathrm{~mm}$

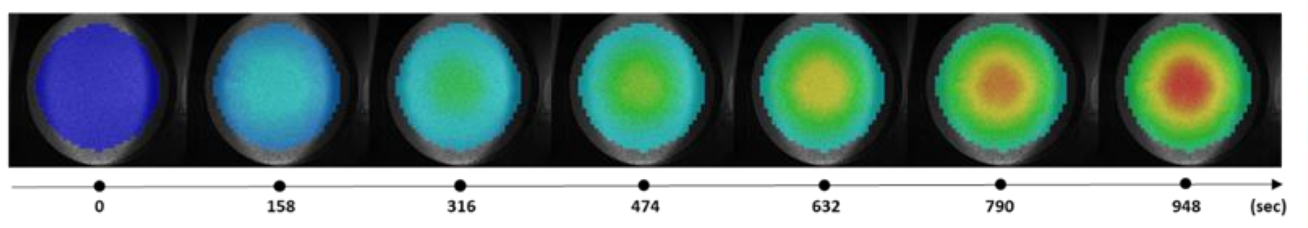

[\%]

0.9

$-0.7$

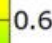

0.5

0.4

$6.0 \mathrm{~mm}$

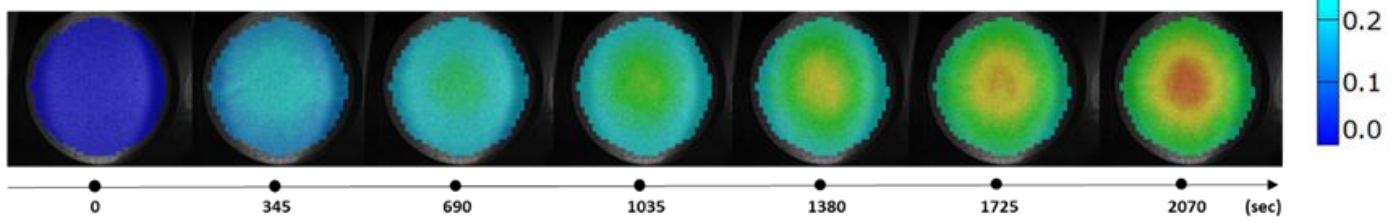


1026 Figure 5:

1027

(a)

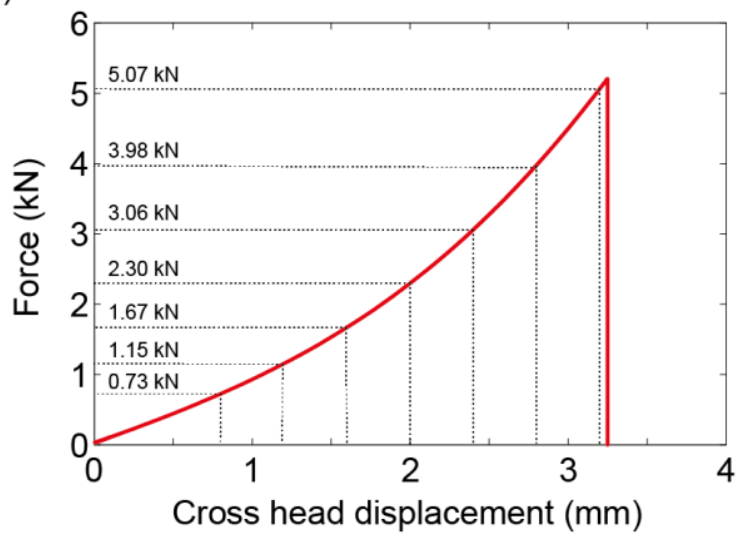

(b)

1028

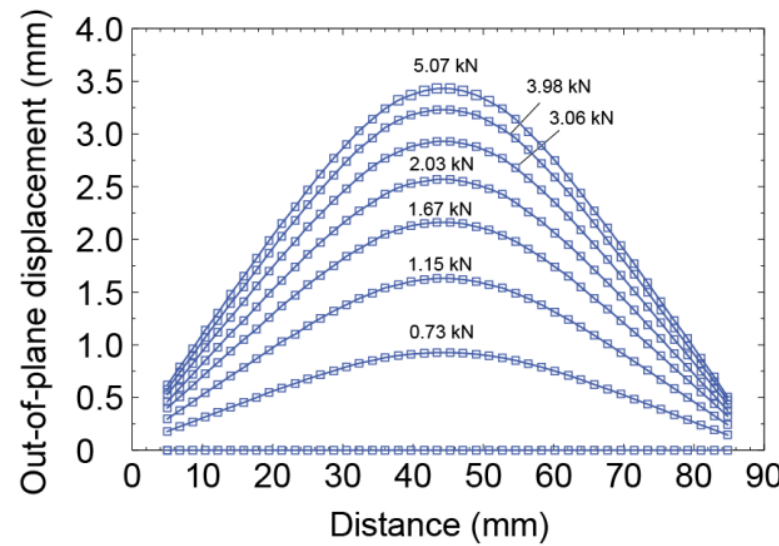

(c)

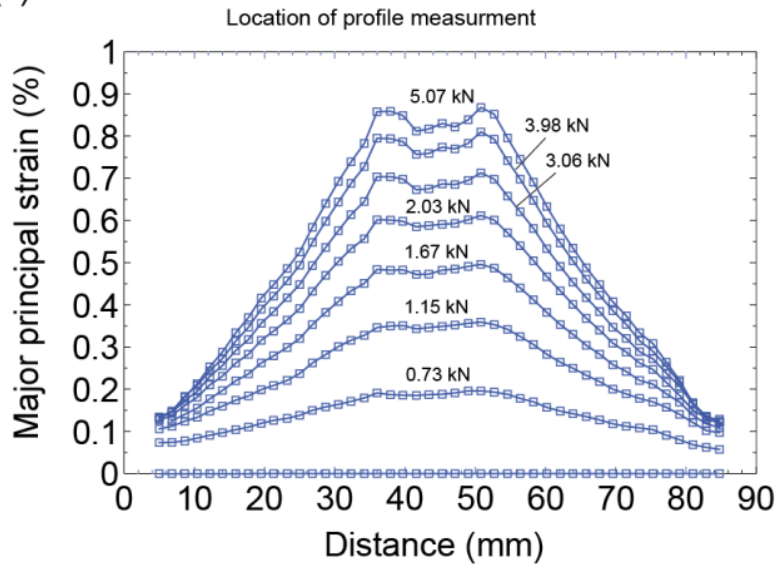


1031 Figure 6:

1032

(a)

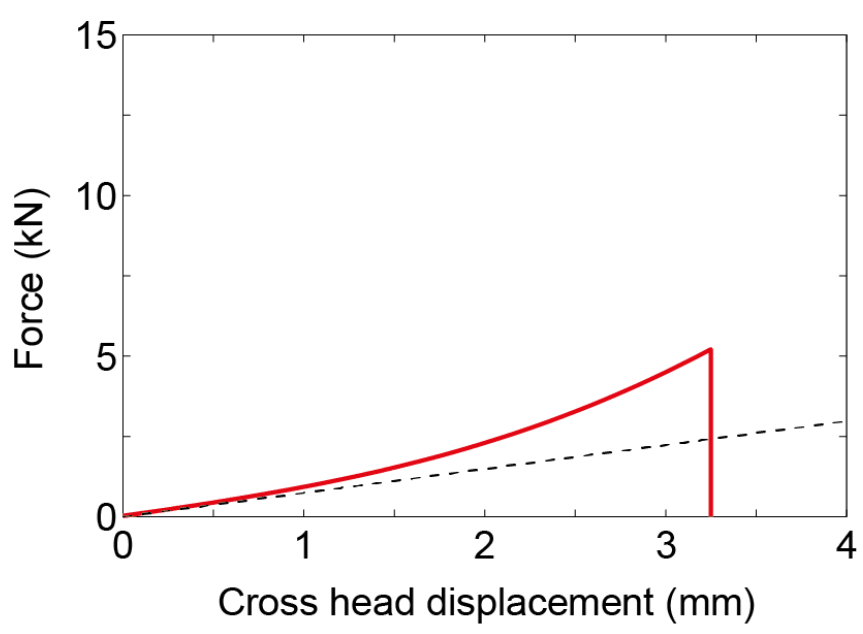

(b)

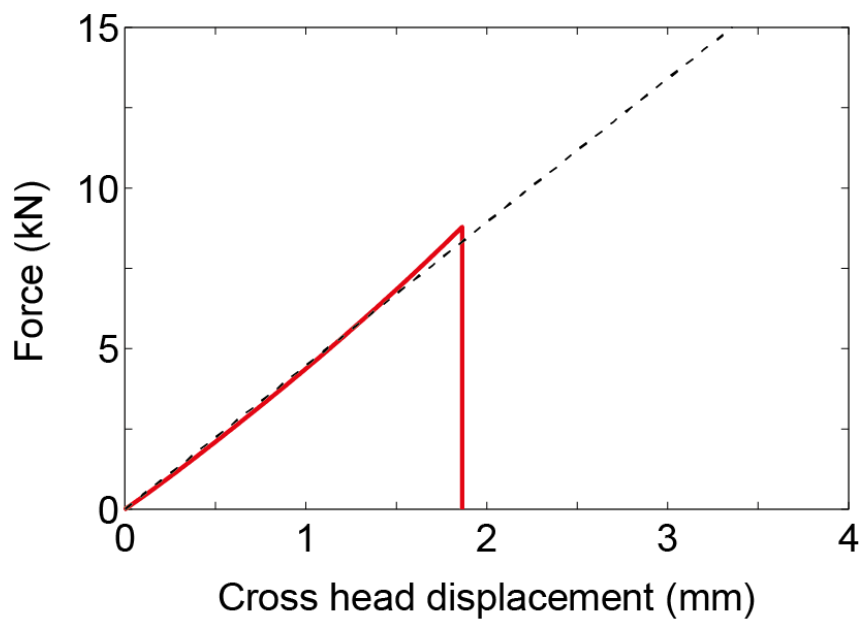

(c)

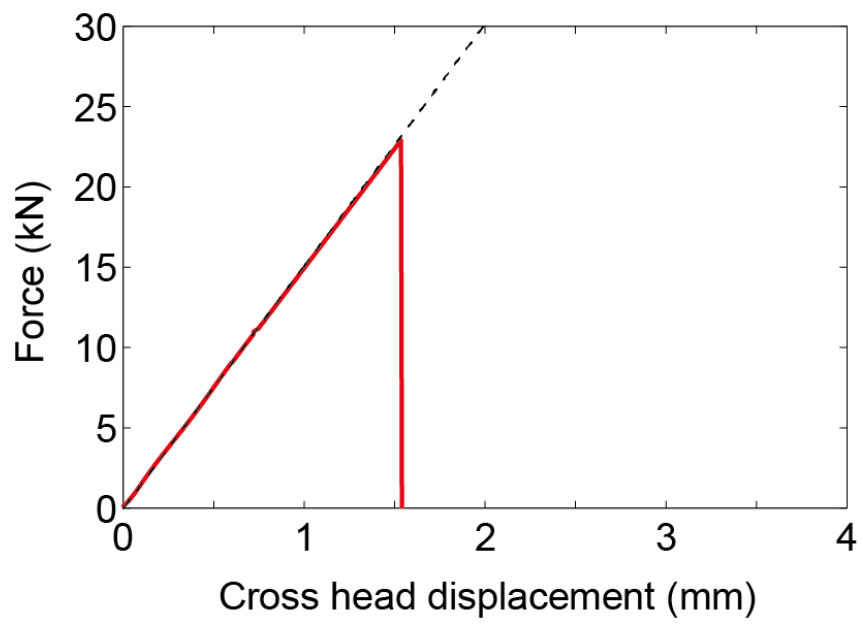

1033

Experiment - - - Linear bending theory (Eq. 1) 
1035 Figure 7:

1036

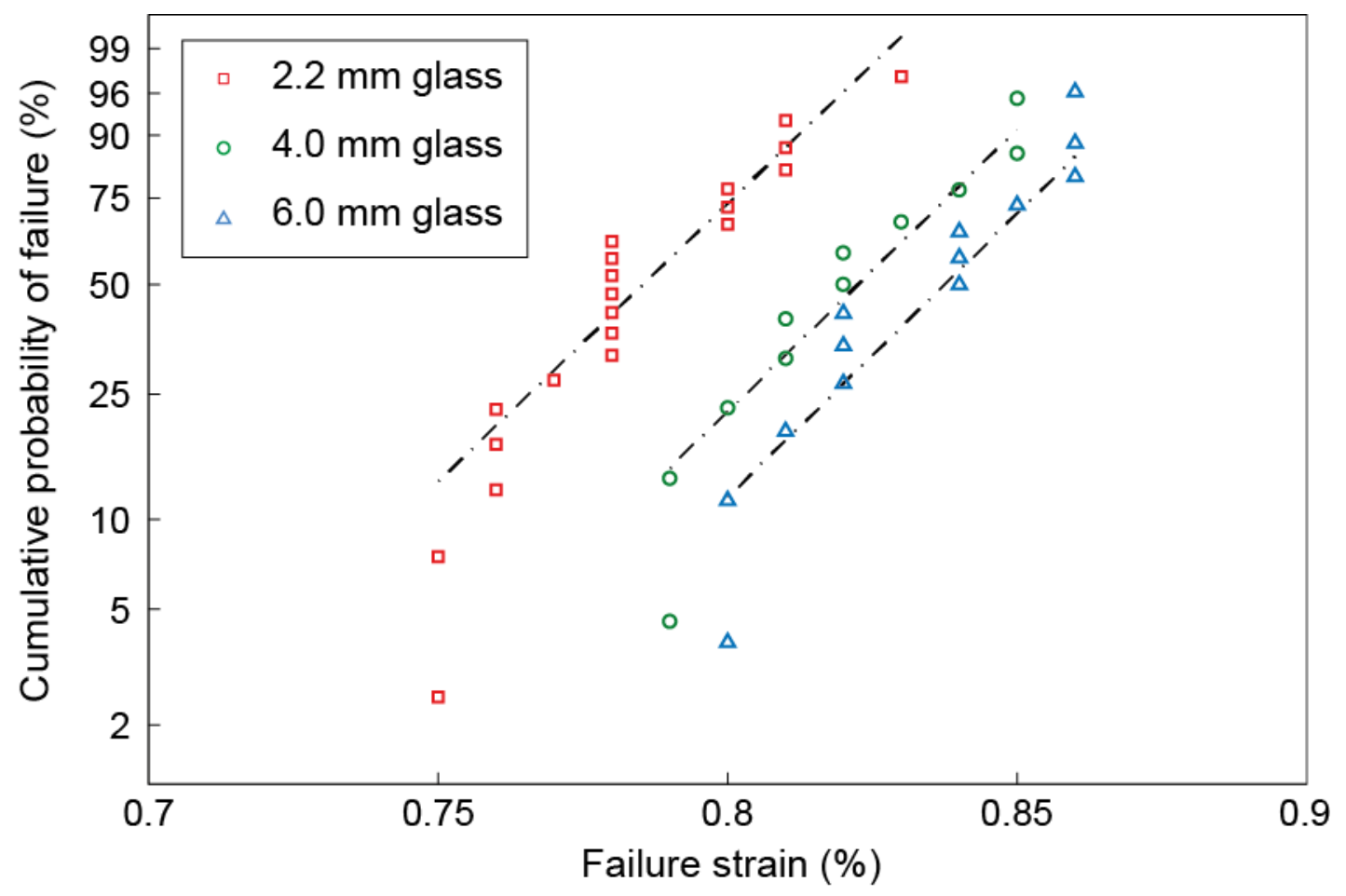

1037

1038 


\section{Figure 8:}

1040

(a)

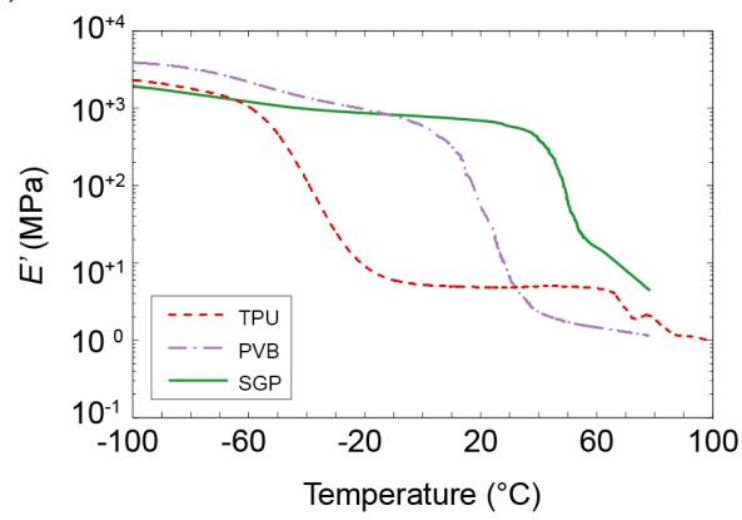

(c)

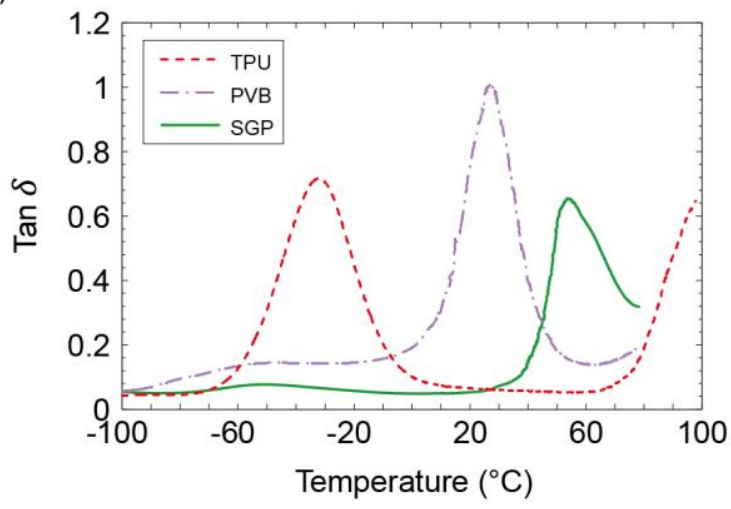

(b)

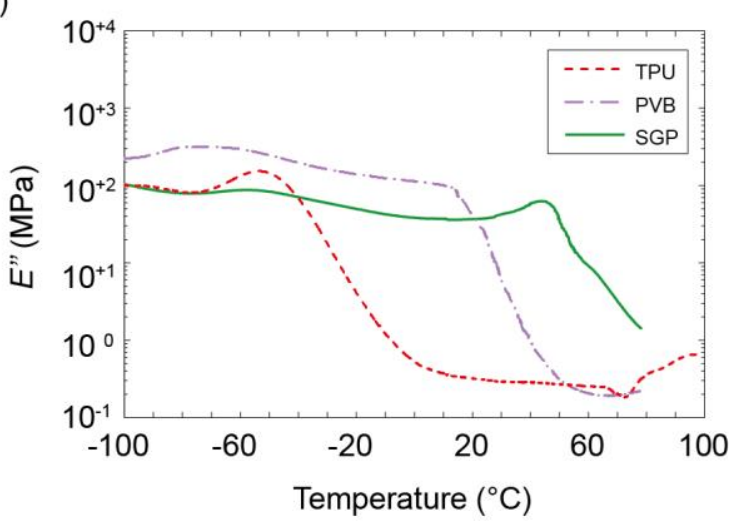

(d)

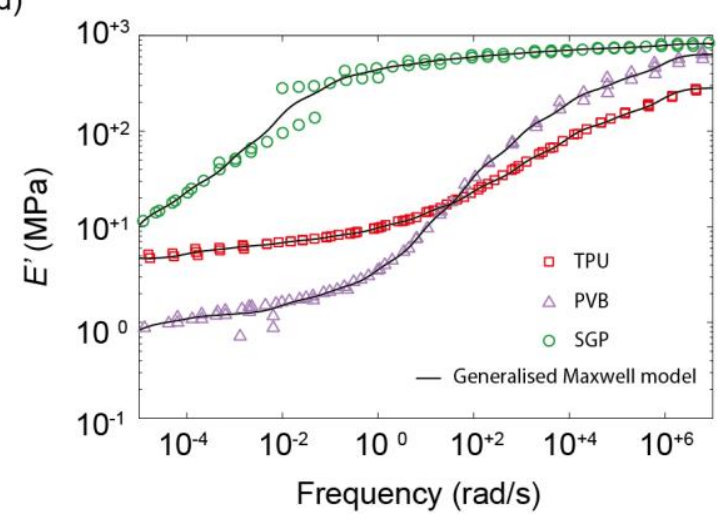

1042 
1043 Figure 9:

1044

1045
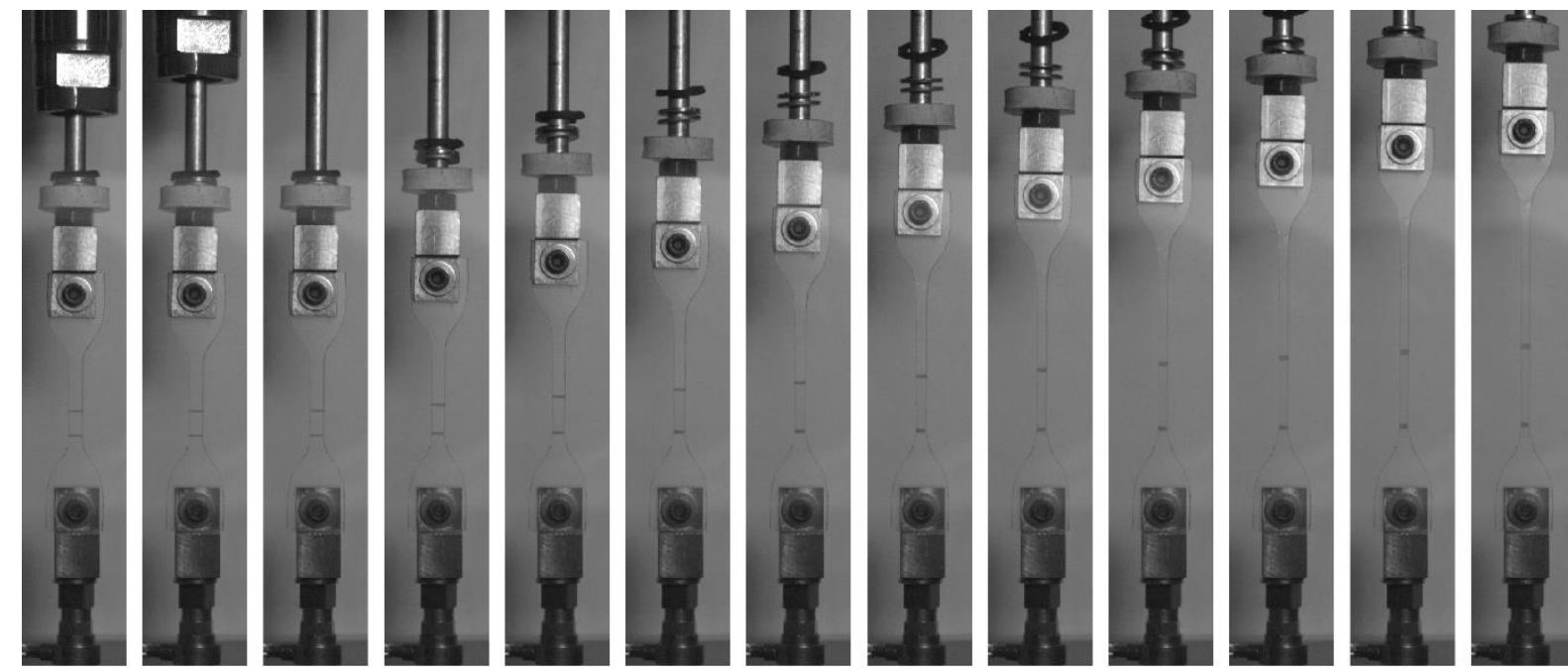

1046 
1047 Figure 10:

1048
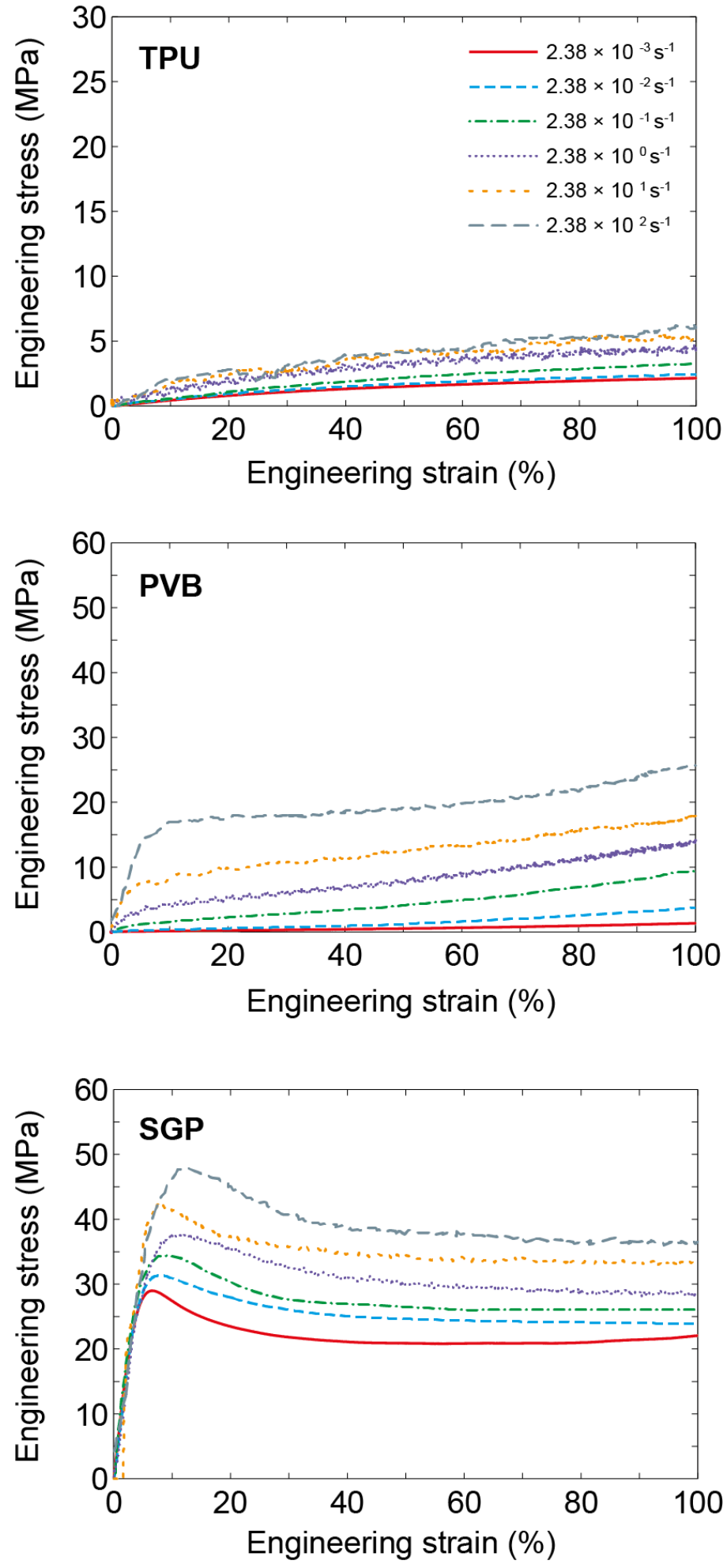

1050 
(a)

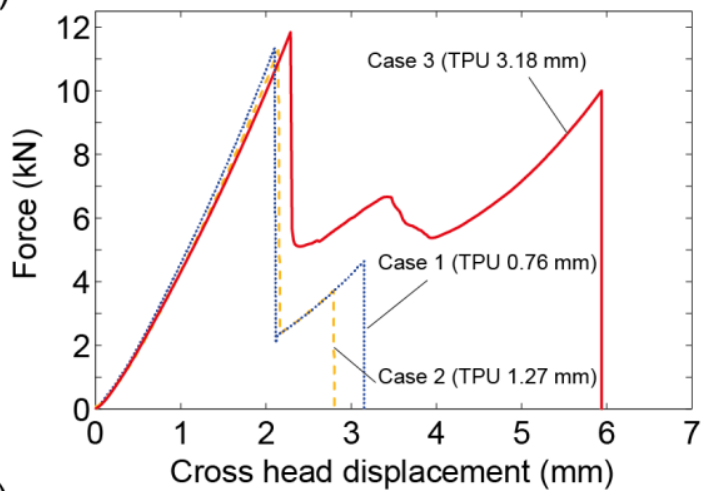

(c)

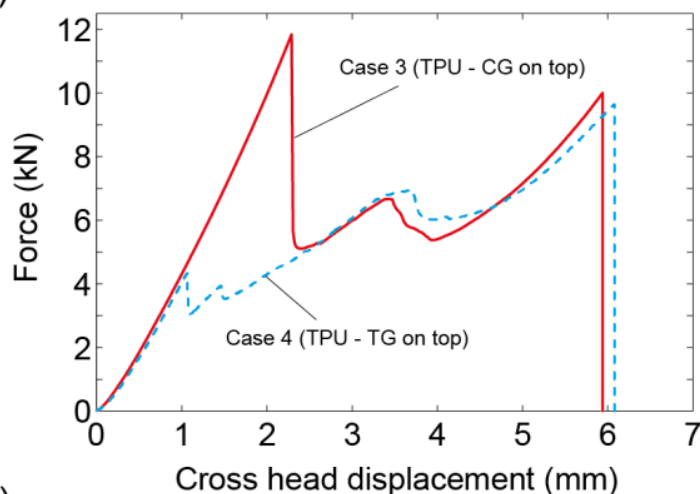

(e)

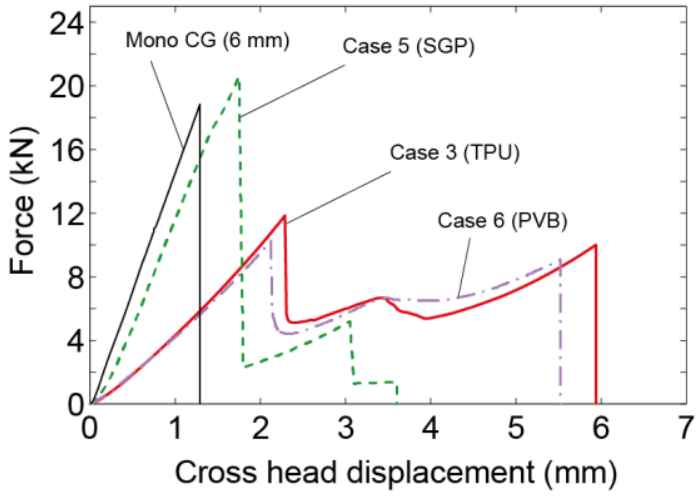

(g)

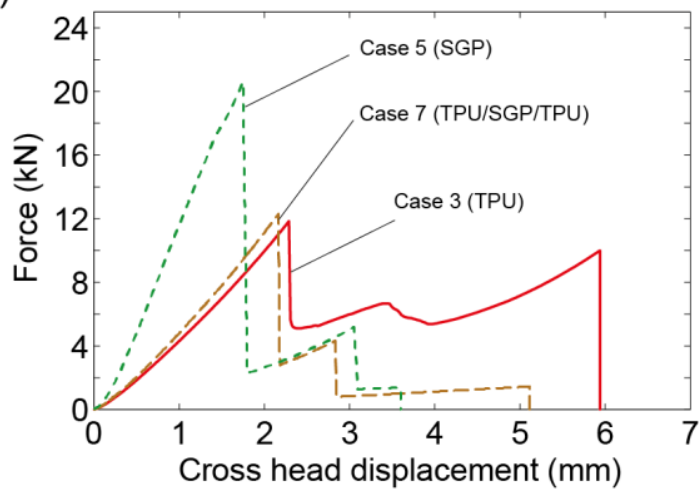

(b)

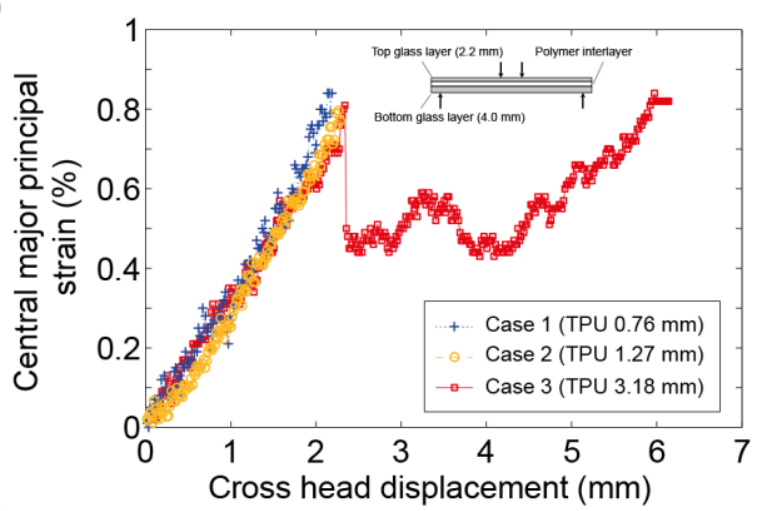

(d)

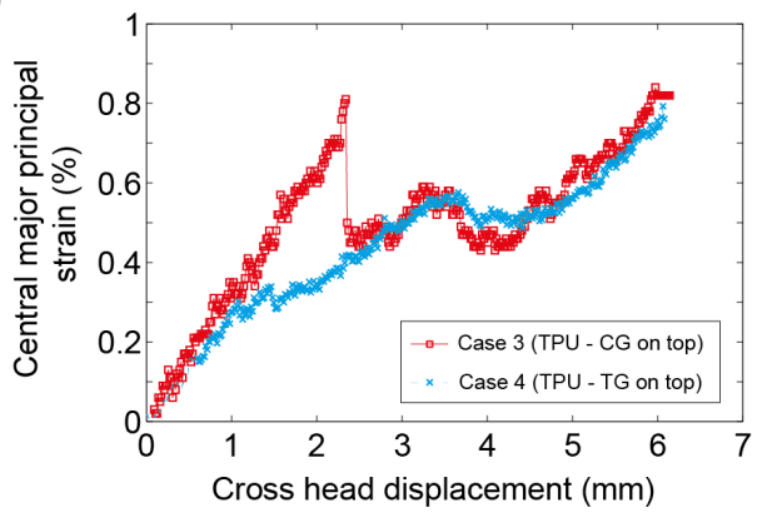

(f)

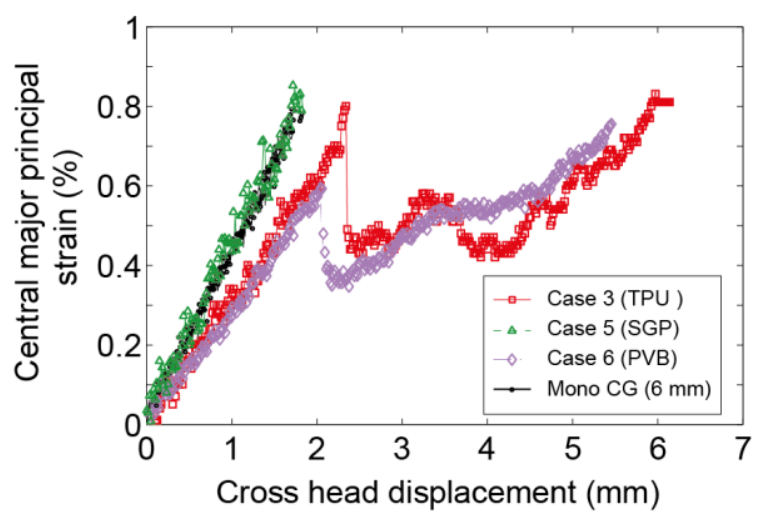

(h)

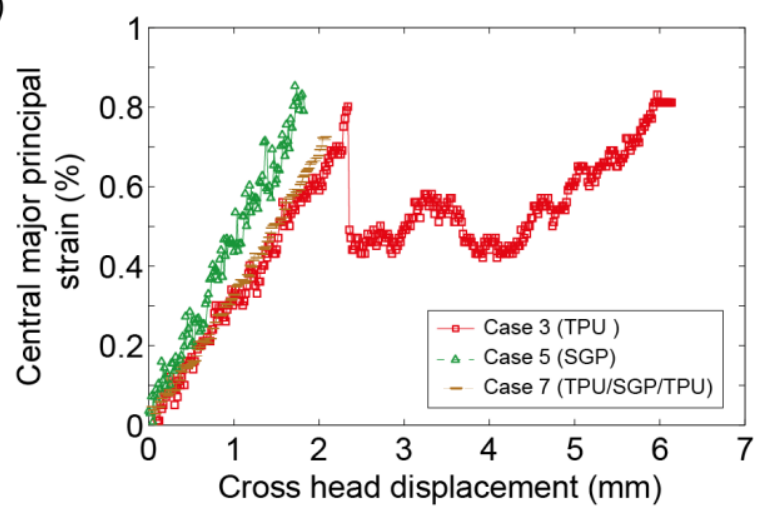


(a)

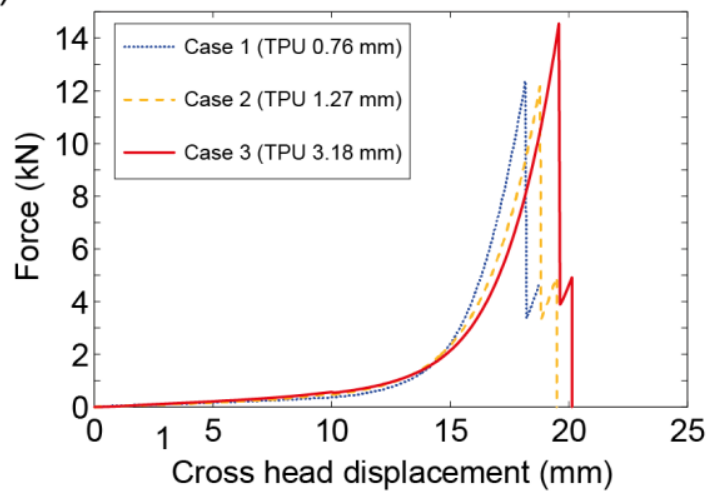

(c)



(e)

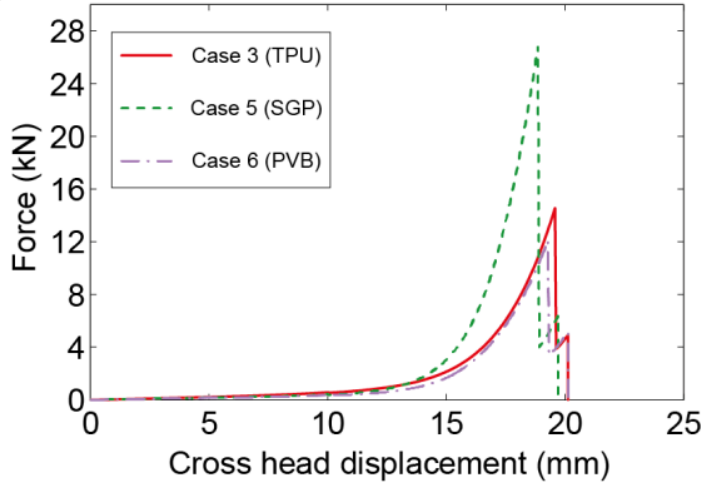

(g)

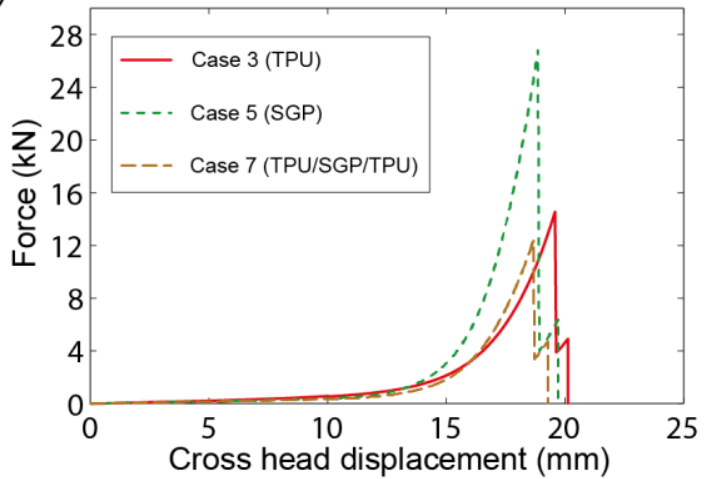

(b)

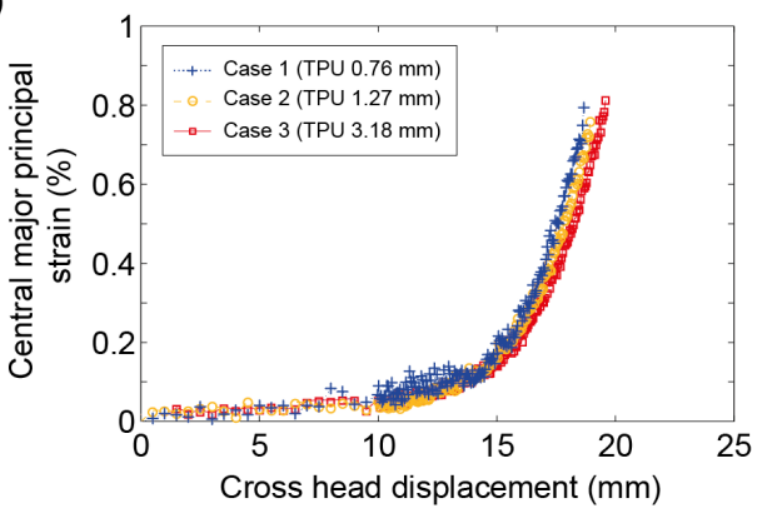

(d)

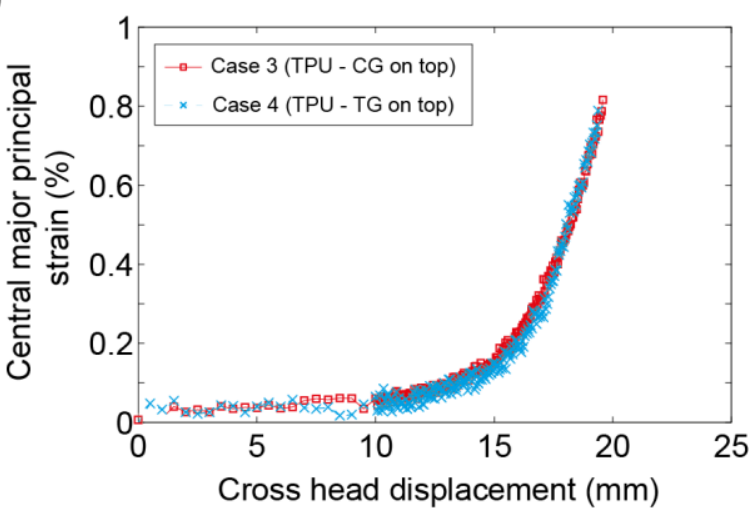

(f)

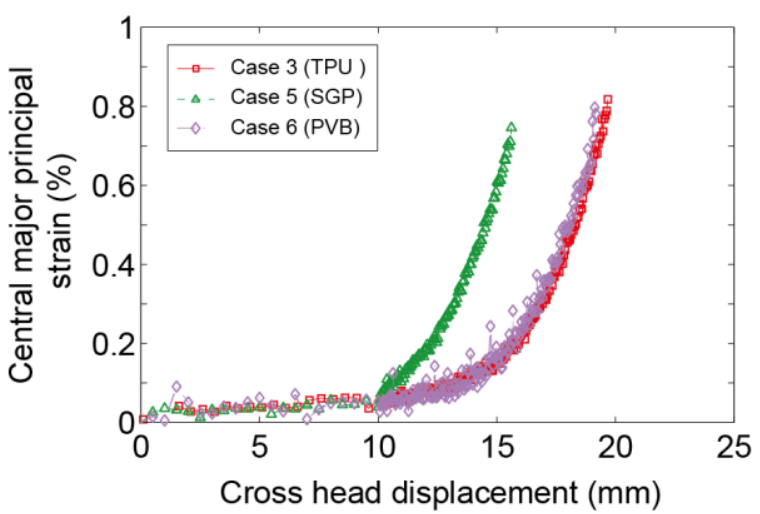

(h)

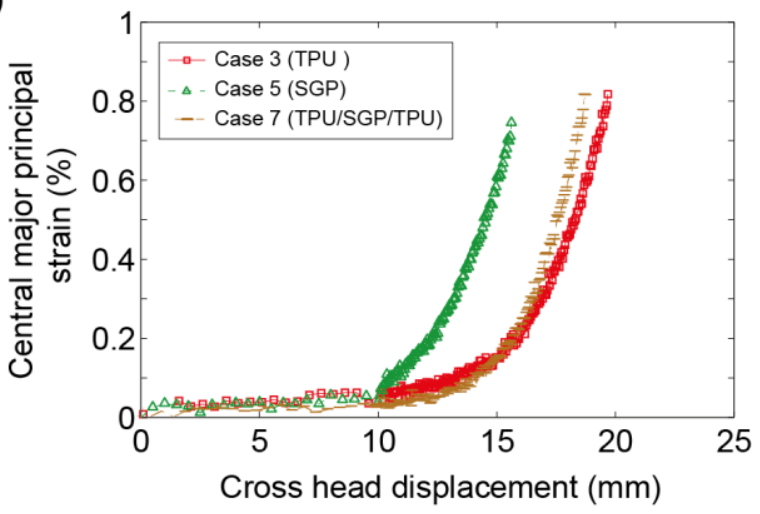


1059 Figure 13:

1060

(a)

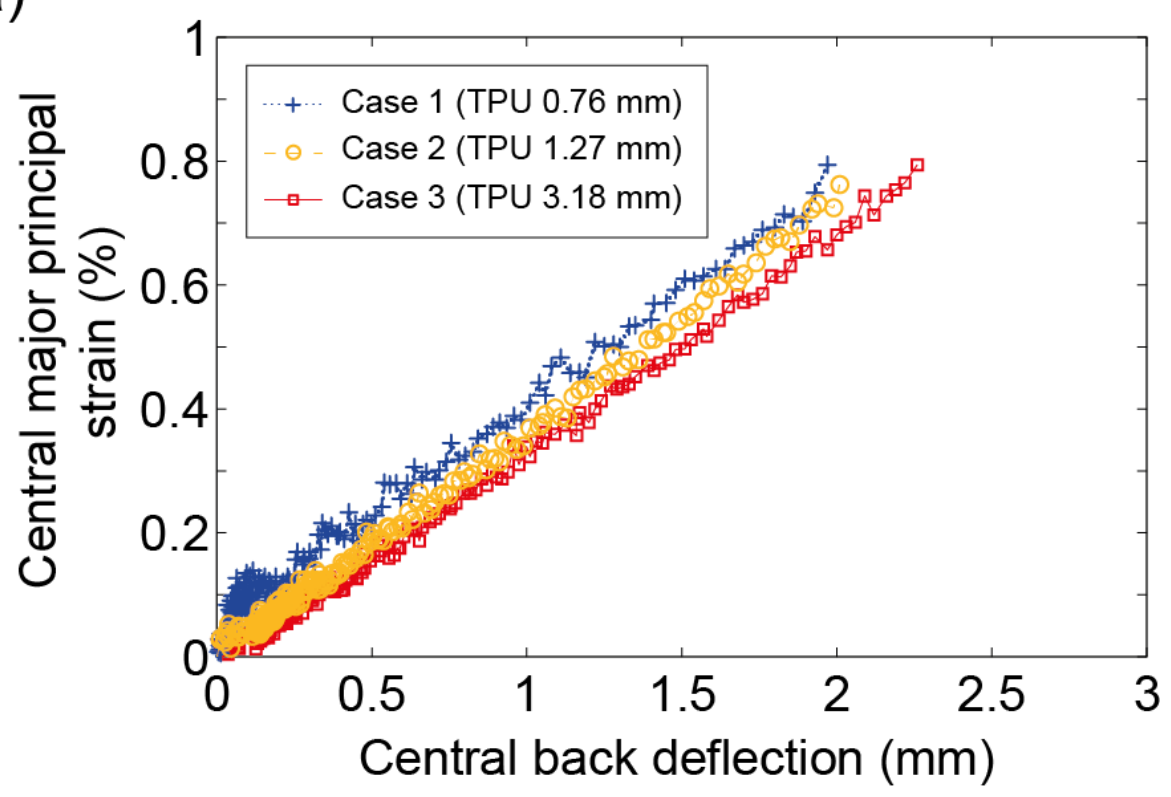

(b)

1061

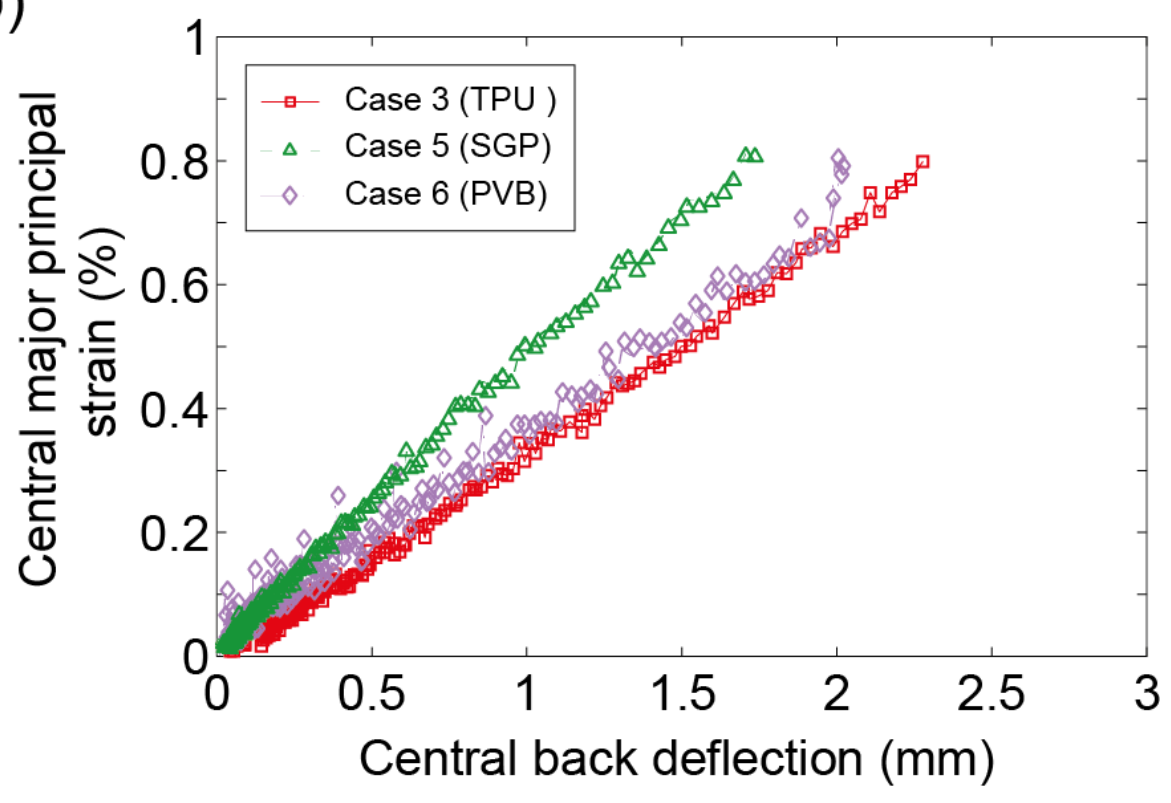

1062 


\section{Figure 14:}

1064

(a)

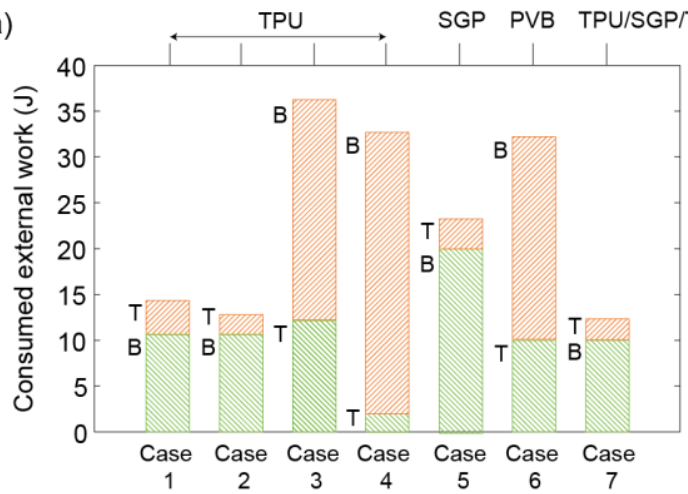

1065 Polymer interlayer

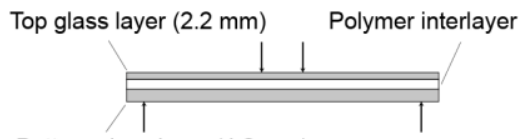

Bottom glass layer $(4.0 \mathrm{~mm})$ (b)

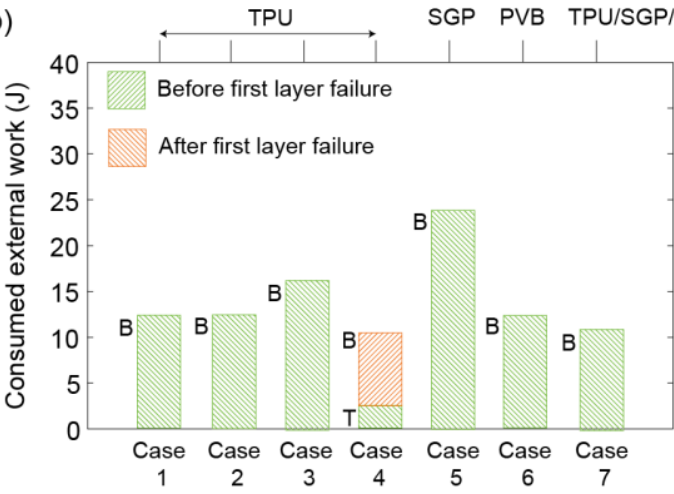

Top glass layer $(2.2 \mathrm{~mm})$ Polymer interlayer ||W||W||W||.

1066 
1067 Figure 15:

1068

(a)

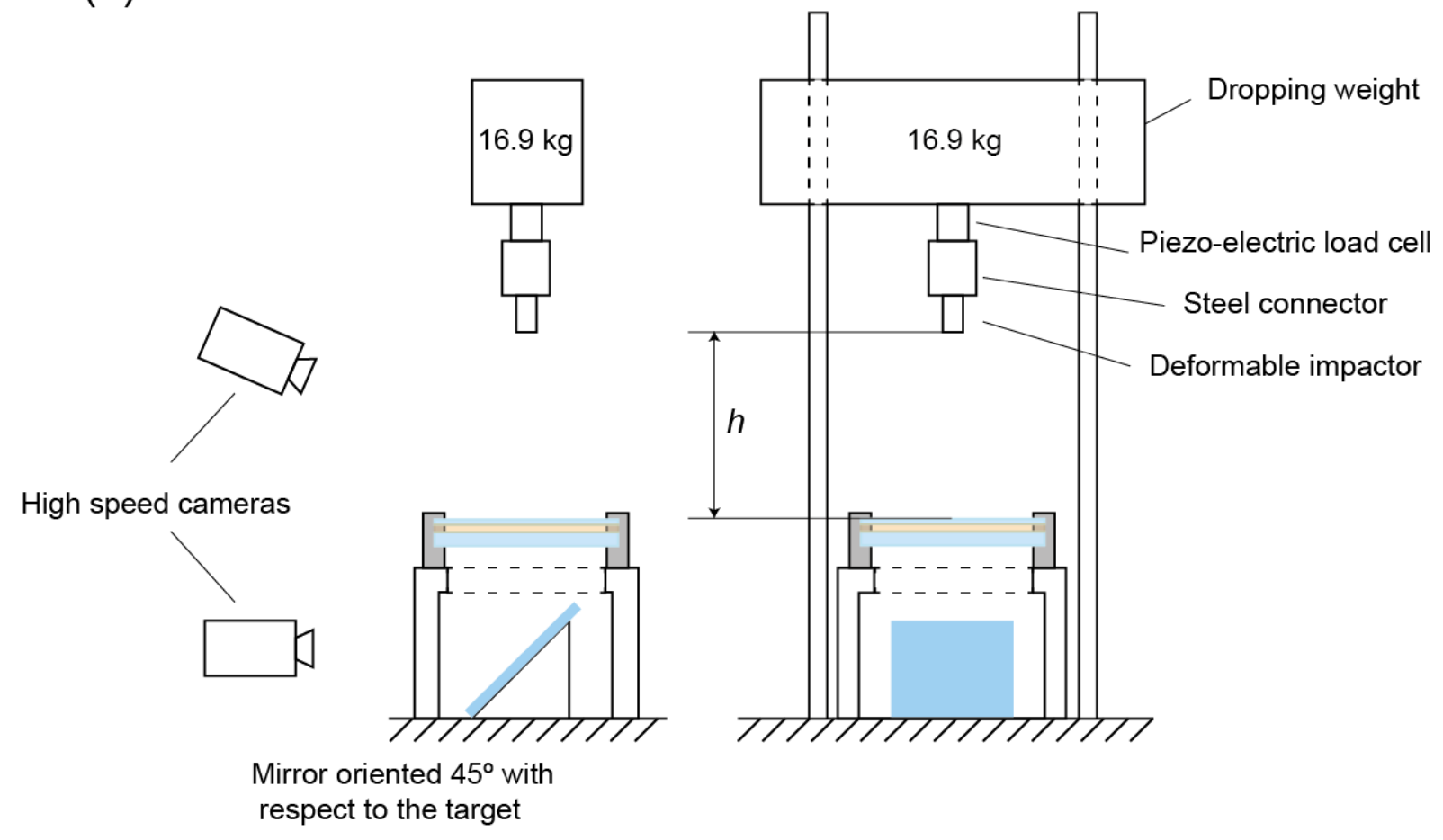

(b)

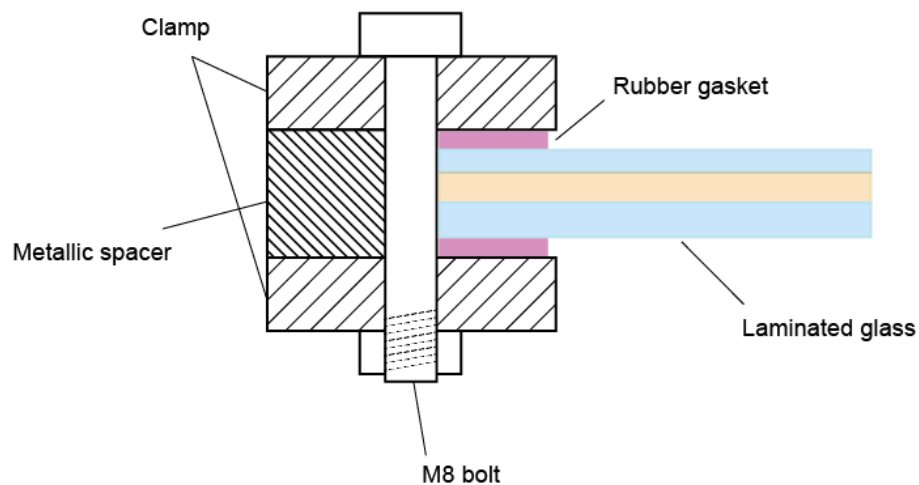


1073 Figure 16:

1074

(a) Dropping mass

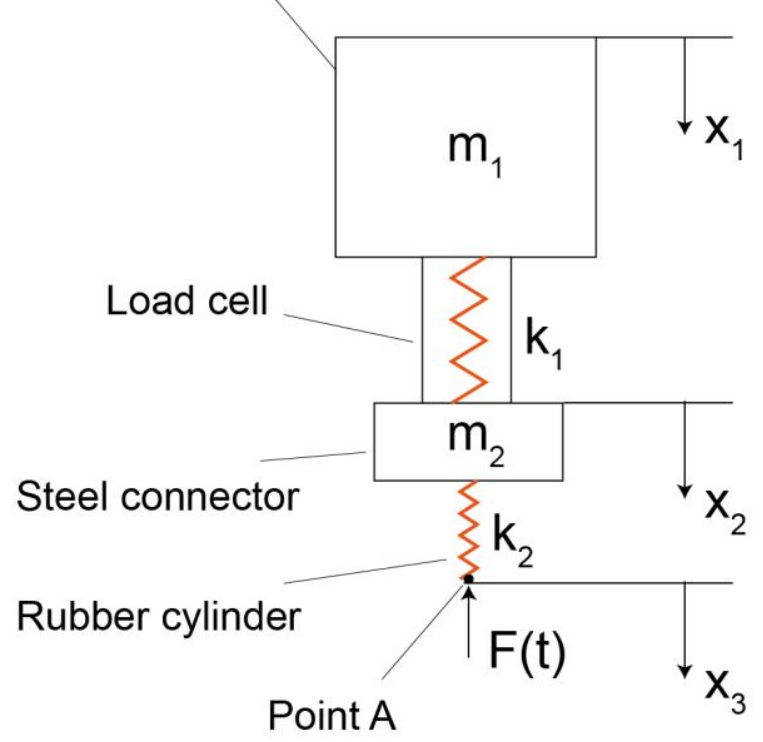

(b)

(c)

(d)
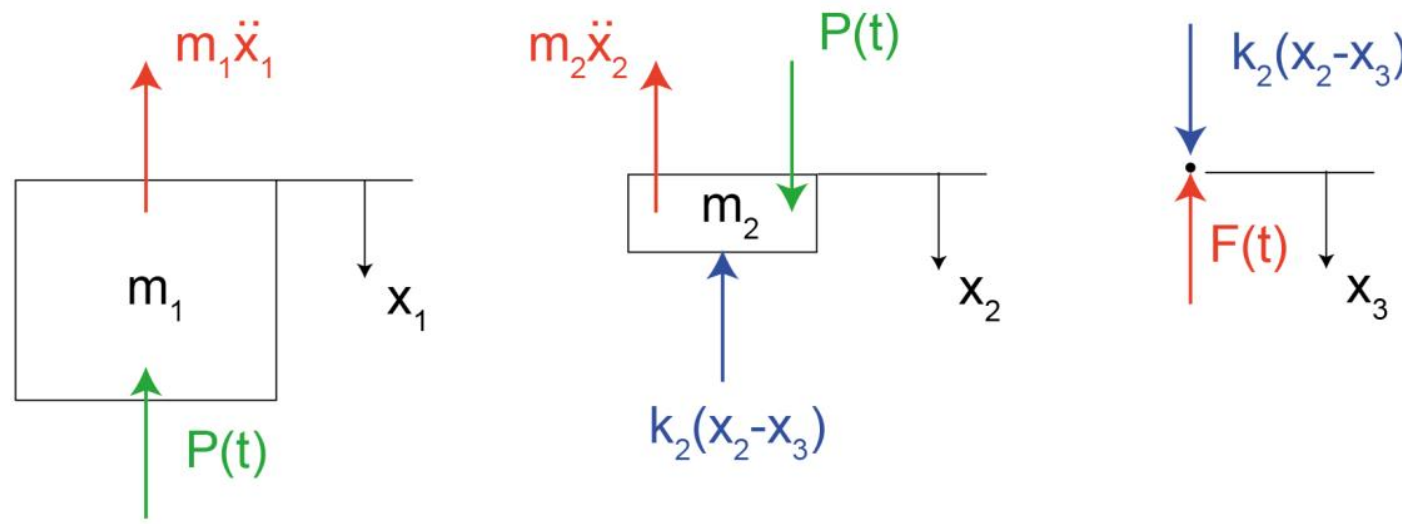

1075

$P(t)=k_{1}\left(x_{1}-x_{2}\right)$

1076 
$1077 \quad$ Figure 17

1078

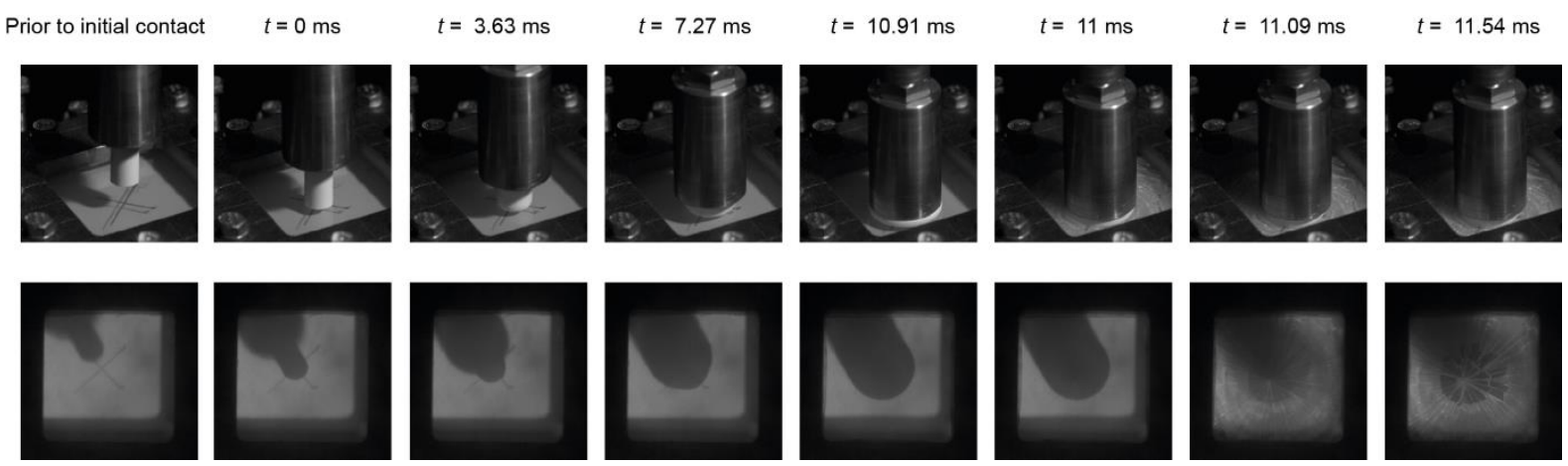

1079

1080 
1081 Figure 18:

1082

(a)

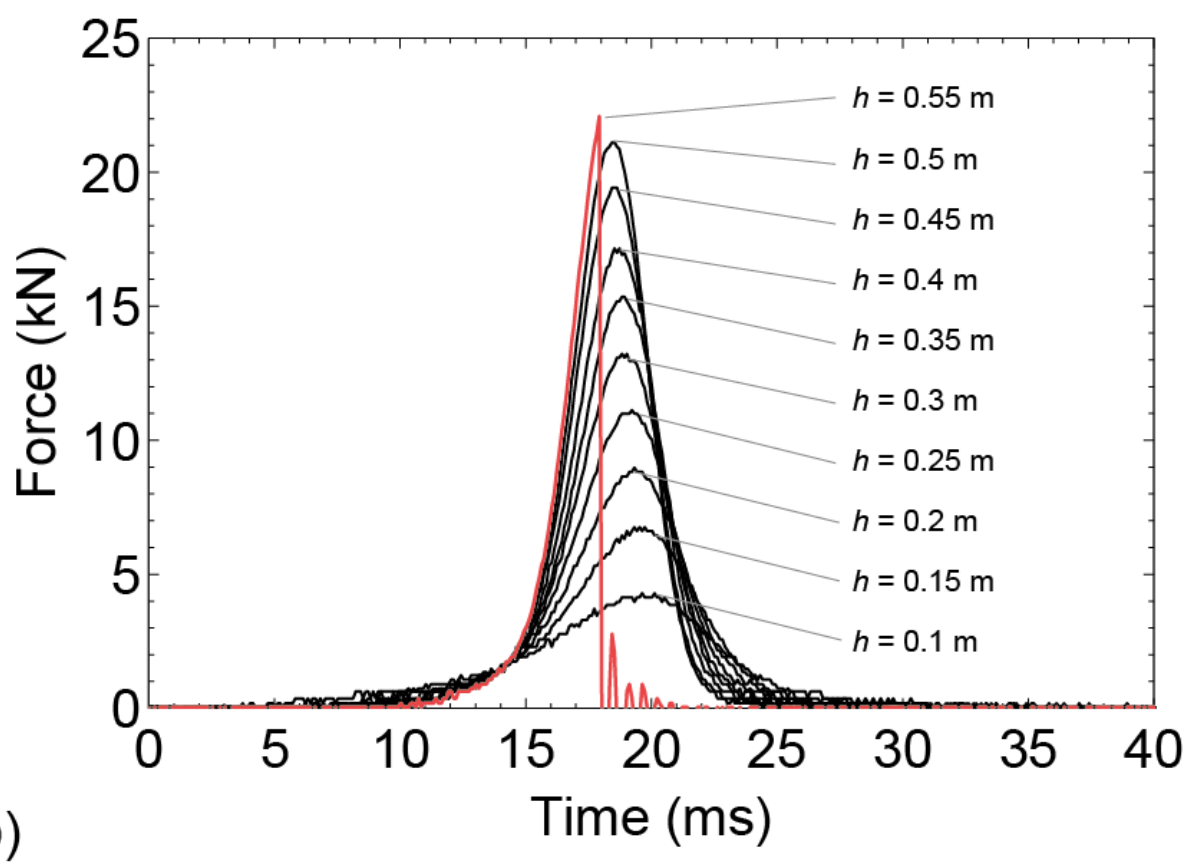

(b)

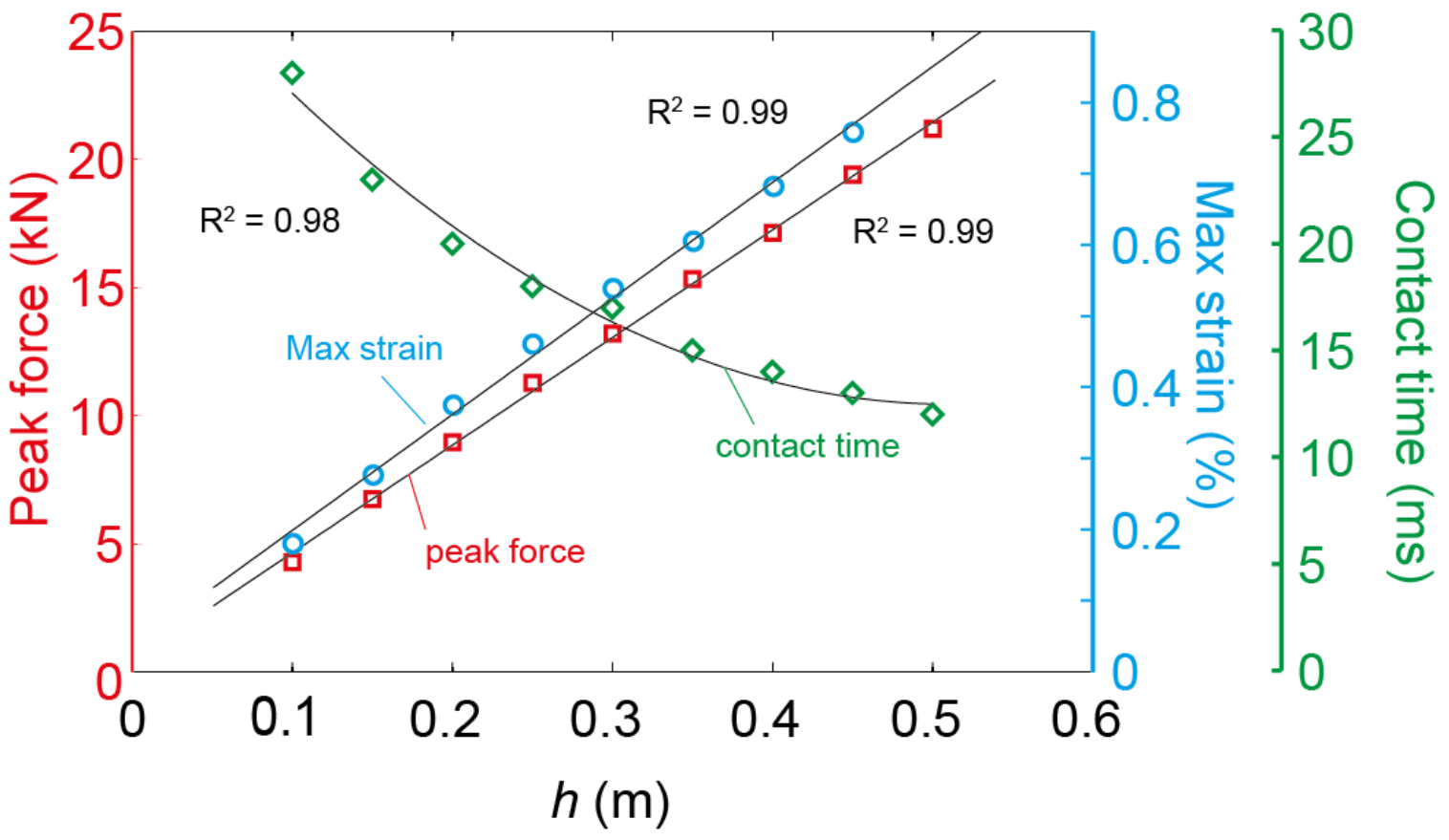

1084

1085 
1086 Figure 19:

1087

(a)

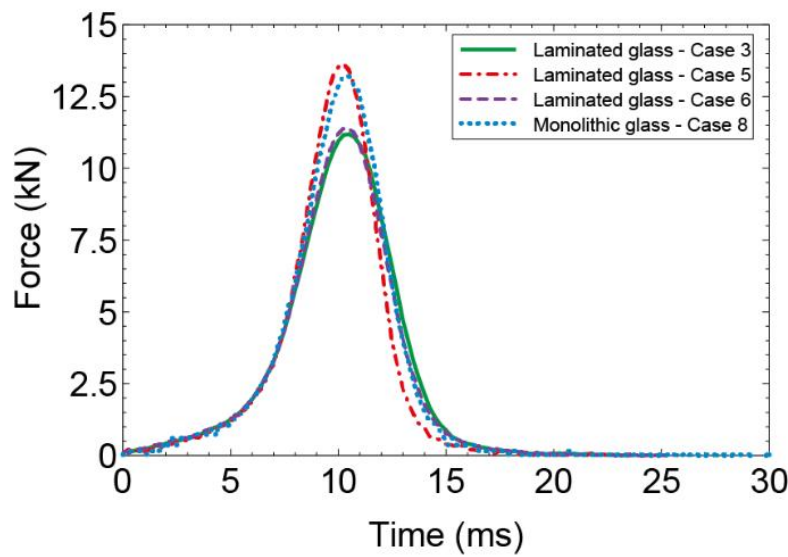

(b)

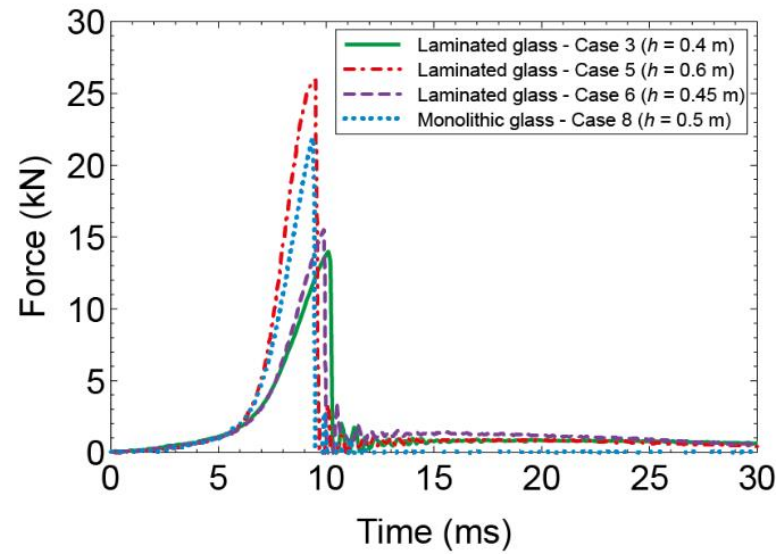

(c)
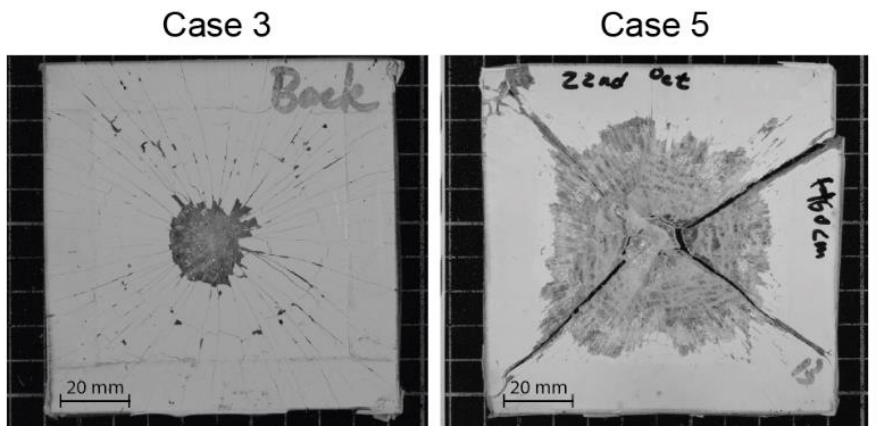

Case 6

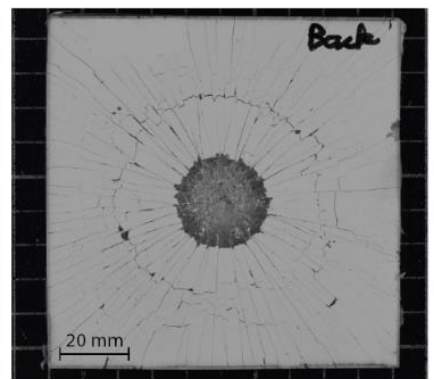


1090 Figure 20:

1091

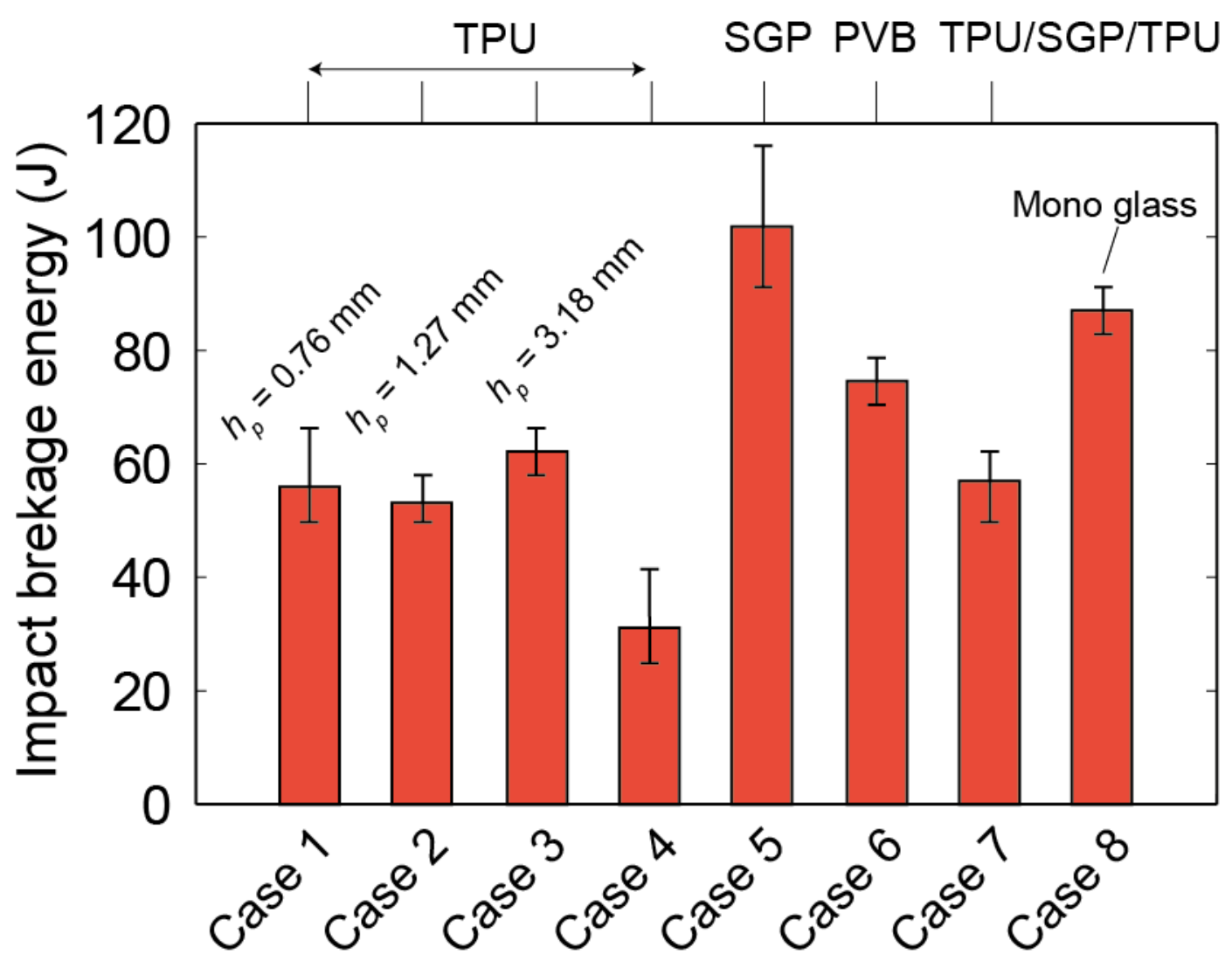

1093 
1094 Figure 21:

1095

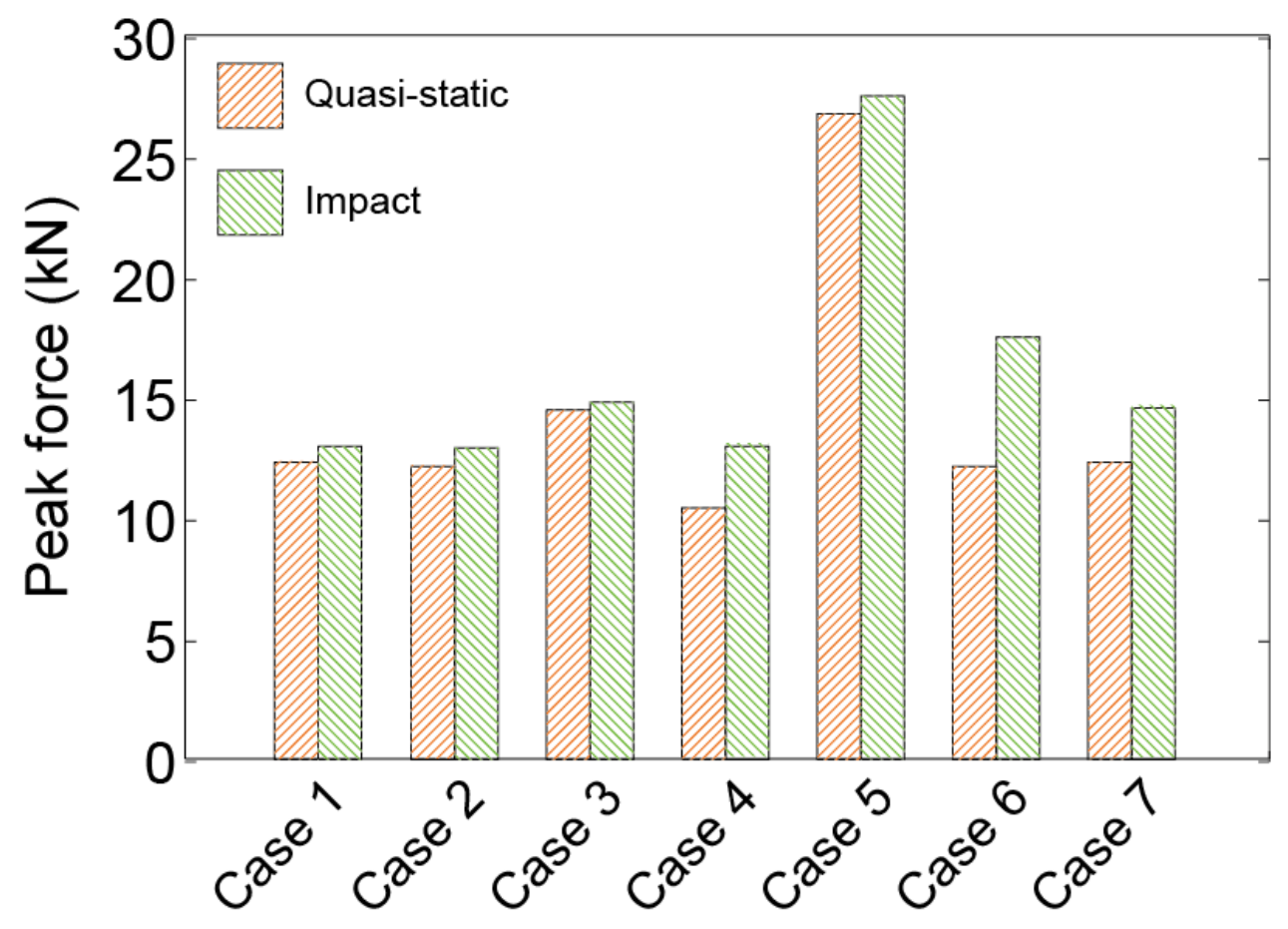

1096

1097 
1098 Figure 22:

1099

1100

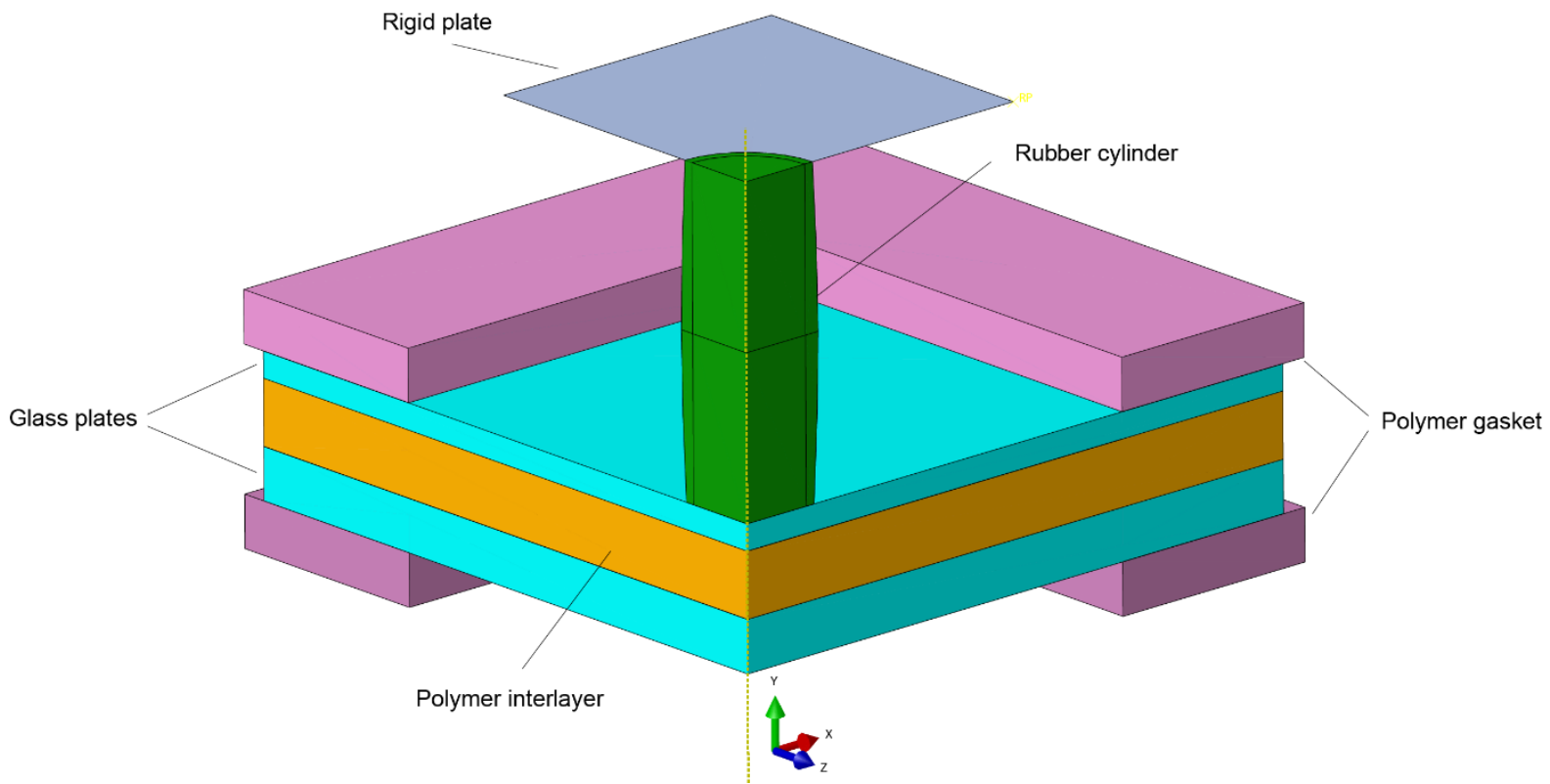

1101 
1102 Figure 23:

1103

$t=0 \mathrm{~ms}$

$t=6 \mathrm{~ms}$

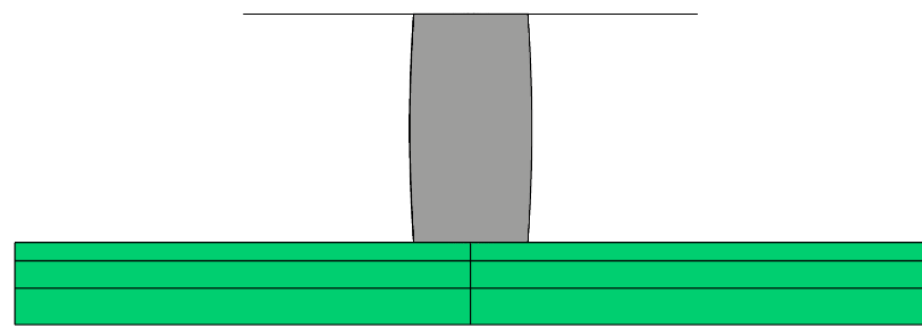

S, Max. Principal (Abs)

(Avg: 75\%)

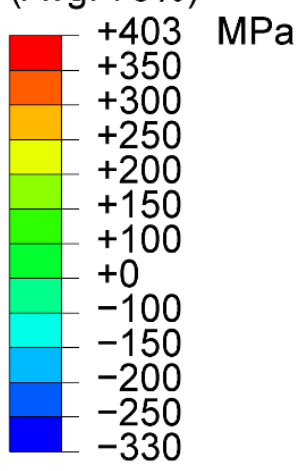

$t=9 \mathrm{~ms}$

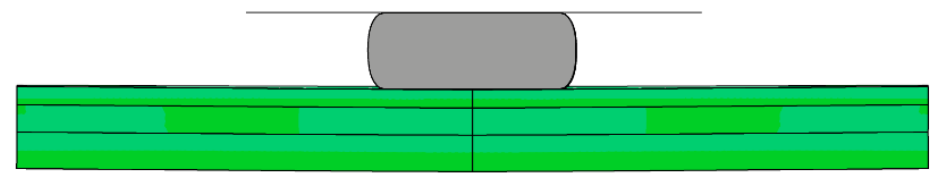

$t=12 \mathrm{~ms}$

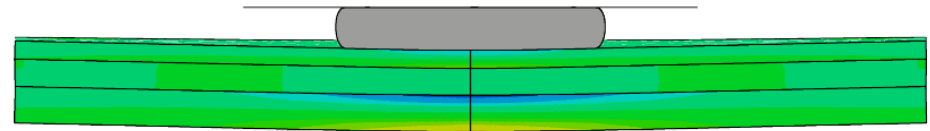

$t=15 \mathrm{~ms}$

1104

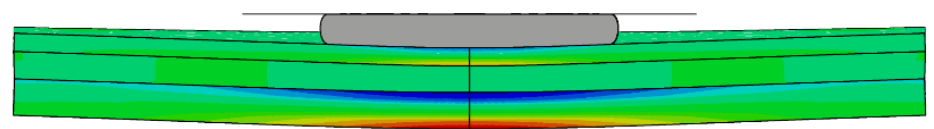


1106 Figure 24:

1107

(a)

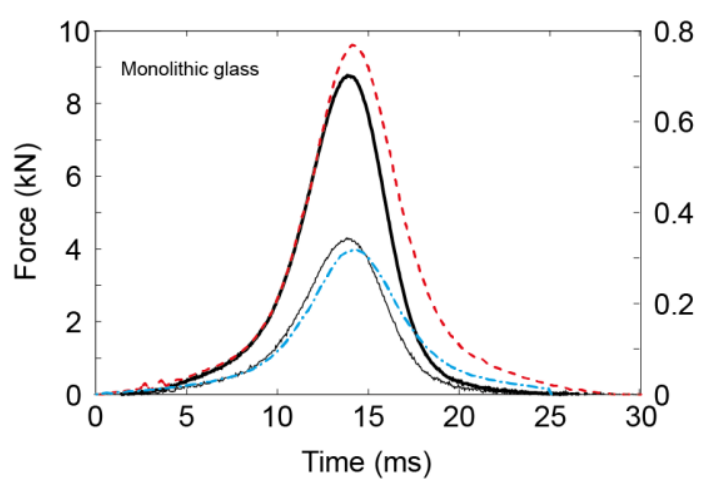

(c)

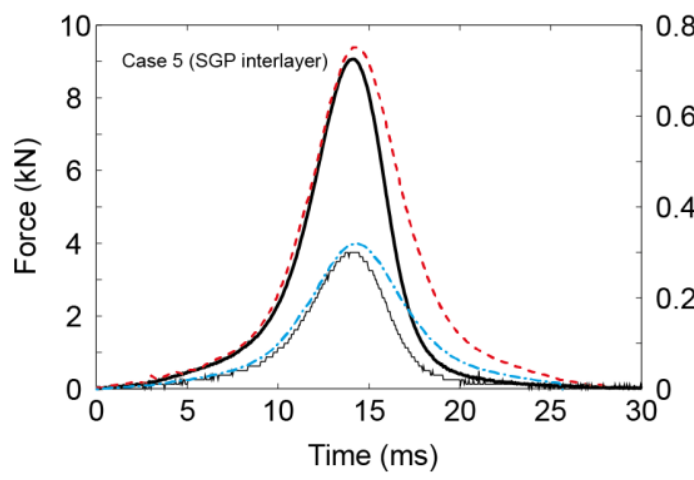

(b)

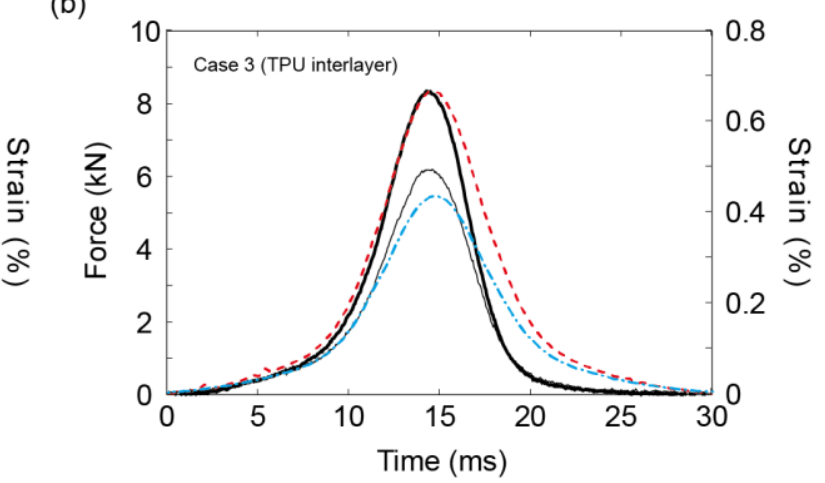

(d)

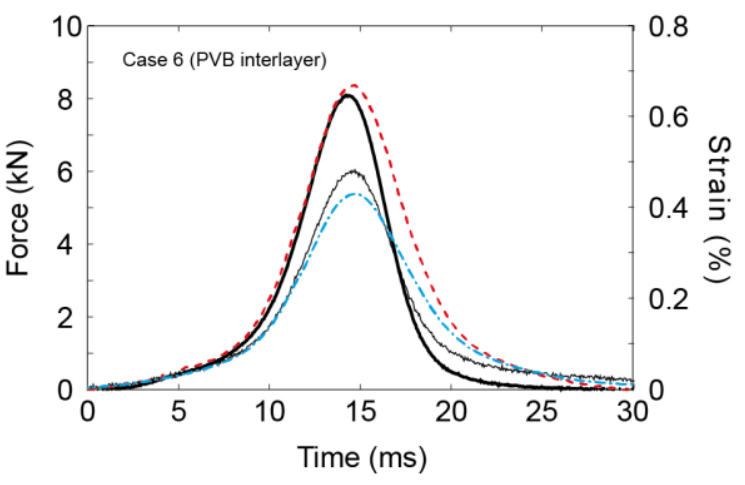


1111 Figure 25:

1112

(a)

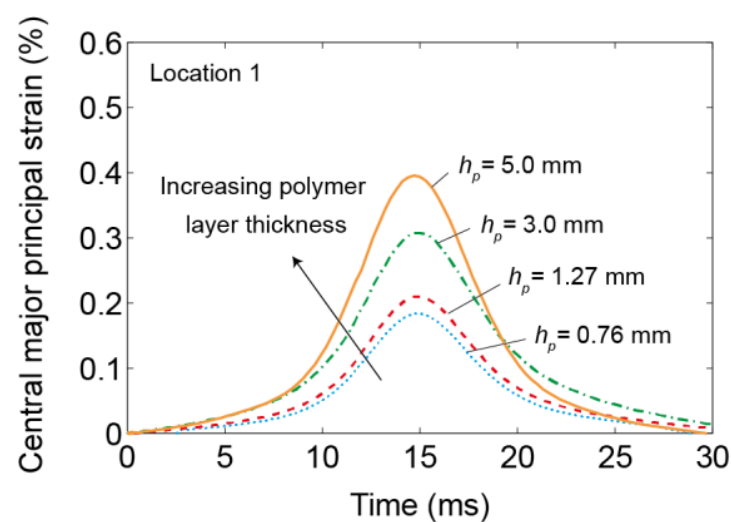

(b)

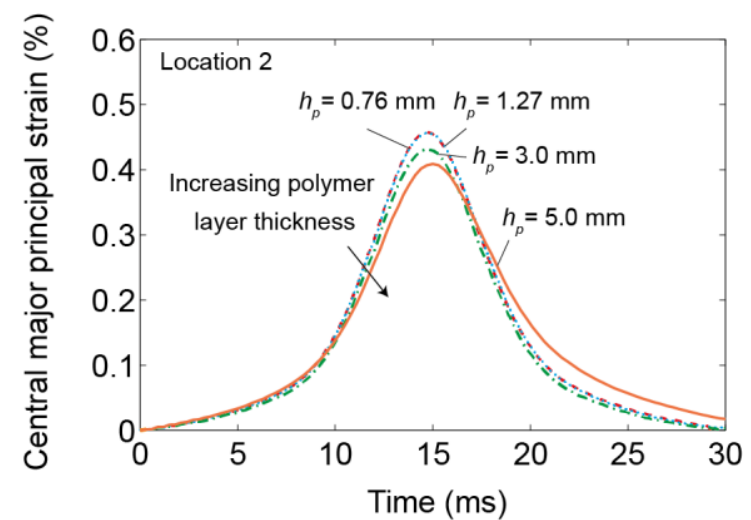

1113

Location 1

1114 
1115 Figure A-1:

1116

(a)

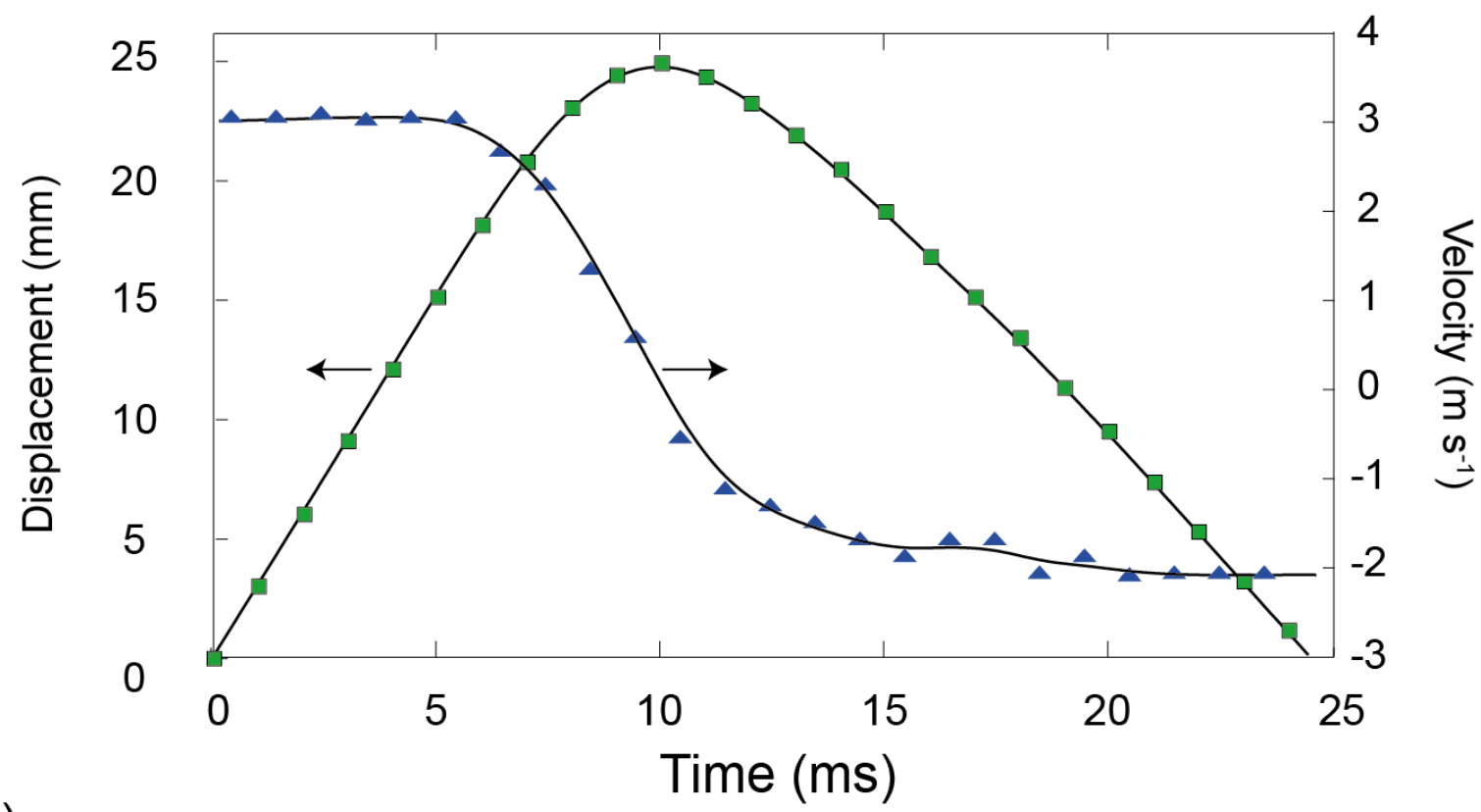

(b)

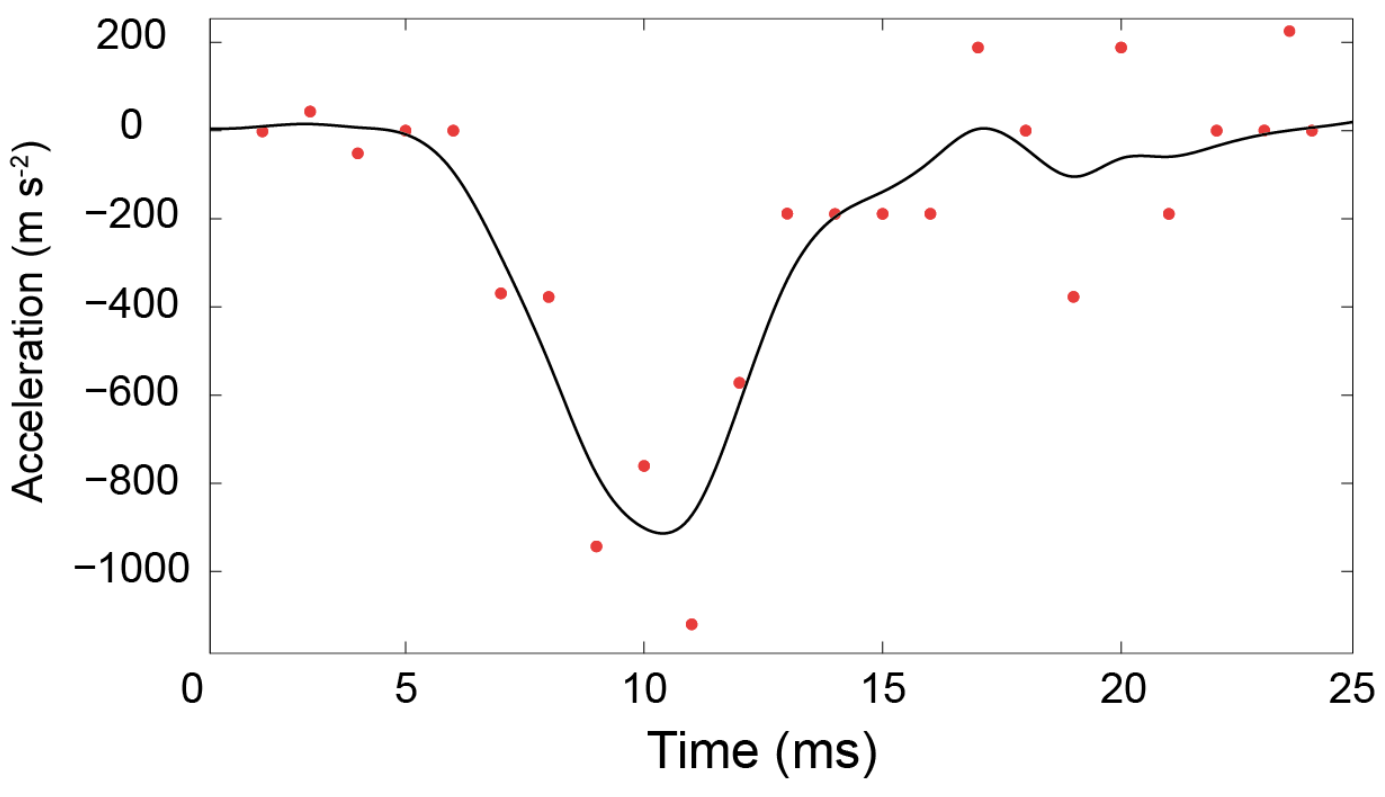

1118 
1119 Figure A-2:

1120

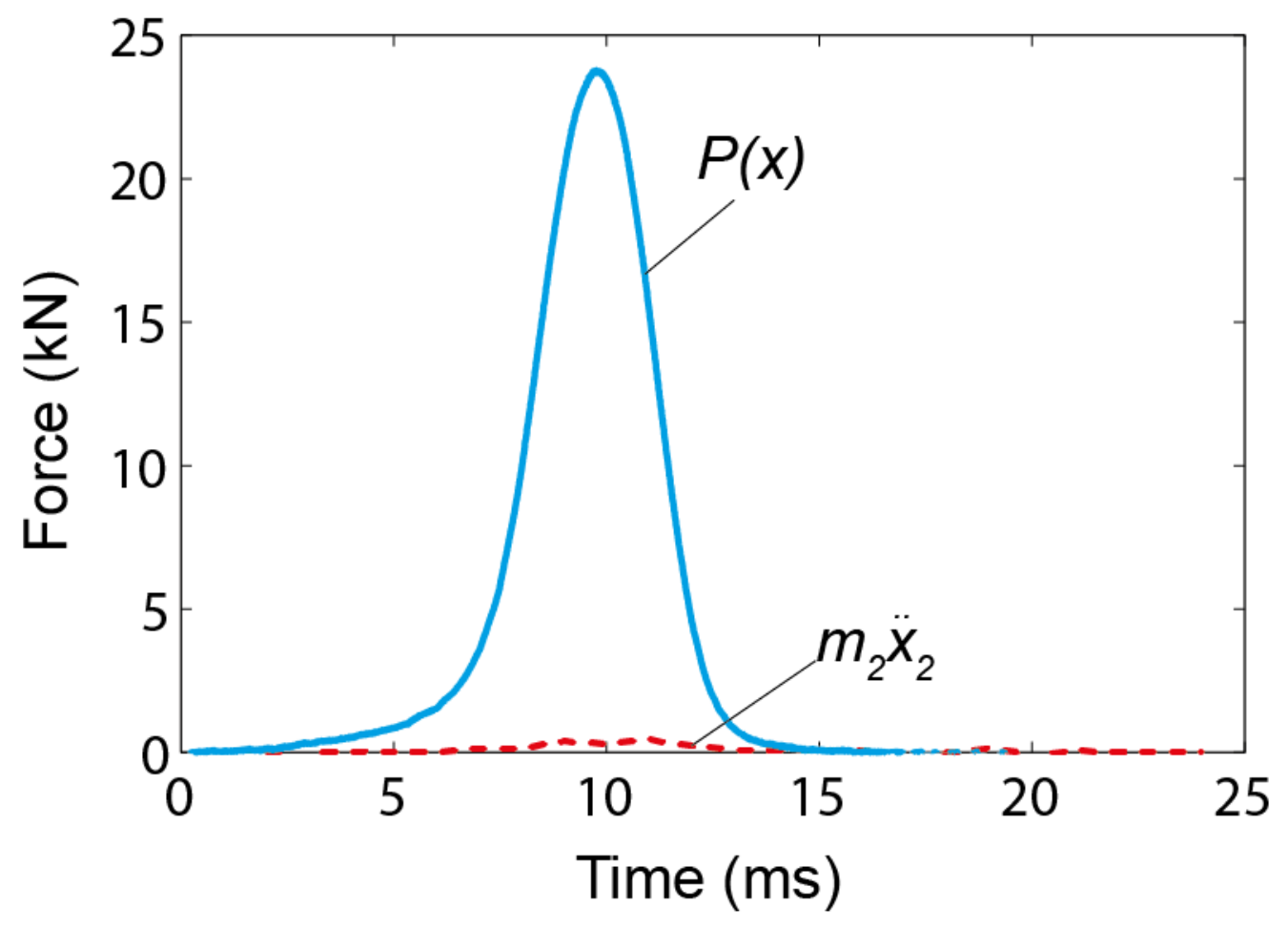

1122 


\begin{tabular}{|c|c|c|}
\hline Configuration & Glass and polymer layers & $\begin{array}{l}\text { Average } \\
\text { plate } \\
\text { thickness } \\
\text { (mm) }\end{array}$ \\
\hline Case 1 & $2.2 \mathrm{~mm} \mathrm{CT}^{(\mathrm{i})} / 0.76 \mathrm{~mm} \mathrm{TPU}^{(\mathrm{ii} /} / 4.0 \mathrm{~mm} \mathrm{CT}$ & 7.35 \\
\hline Case 2 & $2.2 \mathrm{~mm} \mathrm{CT}^{(\mathrm{i})} / 1.27 \mathrm{~mm} \mathrm{TPU}(\mathrm{ii} / 4.0 \mathrm{~mm} \mathrm{CT}$ & 9.23 \\
\hline Case 3 & $2.2 \mathrm{~mm} \mathrm{CT}^{(\mathrm{i})} / 1.27+1.91 \mathrm{~mm} \mathrm{TPU}(\mathrm{ii} / 4.0 \mathrm{~mm} \mathrm{CT}$ & 11.22 \\
\hline Case 4 &  & 9.39 \\
\hline Case 5 & $2.2 \mathrm{~mm} \mathrm{CT} / 1.52+1.52 \mathrm{~mm} \mathrm{SGP}^{(\mathrm{iv})} / 4.0 \mathrm{~mm} \mathrm{CT}$ & 9.26 \\
\hline Case 6 & $2.2 \mathrm{~mm} \mathrm{CT} / 1.52+1.52 \mathrm{~mm} \mathrm{PVB}^{(\mathrm{v})} / 4.0 \mathrm{~mm} \mathrm{CT}$ & 9.11 \\
\hline Case 7 & $2.2 \mathrm{~mm} \mathrm{CT} / 0.38 \mathrm{~mm}$ TPU/2.28 mm SGP/ $0.38 \mathrm{~mm}$ TPU $/ 4.0 \mathrm{~mm} \mathrm{CT}$ & 9.45 \\
\hline Case 8 & $6.0 \mathrm{~mm} \mathrm{CT}$ & 6.0 \\
\hline
\end{tabular}

1124

Chemically toughened (CT) glass plate Ionoplast interlayer (SentryGlas® Plus)

Polyvinyl Butyral interlayer 
1133 Table 2:

1134

\begin{tabular}{|c|c|c|}
\hline $\begin{array}{c}\text { Glass thickness } \\
(\mathrm{mm})\end{array}$ & $\begin{array}{c}\varepsilon_{0} \\
(\%)\end{array}$ & $m$ \\
\hline 2.2 & 0.79 & 37.0 \\
\hline 4.0 & 0.84 & 45.6 \\
\hline 6.0 & 0.83 & 43.1 \\
\hline
\end{tabular}

1135

1136 


\begin{tabular}{|c|c|c|c|c|}
\hline \multirow{2}{*}{$i$} & \multicolumn{3}{|c|}{$G_{i} / G_{o}{ }^{*}$} & \multirow{2}{*}{$\tau_{i}(s)$} \\
\cline { 2 - 5 } & TPU & SGP & PVB & \\
\hline 1 & 0.42077 & 0.07767 & 0.39262 & $10^{-6}$ \\
\hline 2 & 0.18113 & 0.03764 & 0.19225 & $10^{-5}$ \\
\hline 3 & 0.19280 & 0.05631 & 0.20957 & $10^{-4}$ \\
\hline 4 & 0.09969 & 0.06501 & 0.12621 & $10^{-3}$ \\
\hline 5 & 0.04750 & 0.07409 & 0.05694 & $10^{-2}$ \\
\hline 6 & 0.01928 & 0.09317 & 0.01536 & $10^{-1}$ \\
\hline 7 & 0.00903 & 0.11867 & 0.00325 & $10^{0}$ \\
\hline 8 & 0.00414 & 0.20551 & 0.00103 & $10^{+1}$ \\
\hline 9 & 0.00307 & 0.18131 & 0.00077 & $10^{+2}$ \\
\hline 10 & 0.00230 & 0.05361 & 0.00010 & $10^{+3}$ \\
\hline 11 & 0.00371 & 0.01856 & 0.00029 & $10^{+4}$ \\
\hline 12 & 0.00004 & 0.01180 & 0.00053 & $10^{+5}$ \\
\hline & & & & \\
\hline & & & & \\
\hline
\end{tabular}

1139

$1140{ }^{*} G_{o}$ is the instantainous shear modulus and it value is equal to: $G_{\infty}+\sum_{i=1}^{n} G_{i}$, where $G_{\infty}$ is the long1141 term shear modulus. $G_{o}$ and $G_{\infty}$ are is $94.6 \mathrm{MPa}$ and $1.56 \mathrm{MPa}$ for TPU, 274.1 MPa and 1.8 MPa for 1142 SGP, and 213.6 MPa and 0.22 MPa for PVB respectively.

1143

1144

1145

1146 